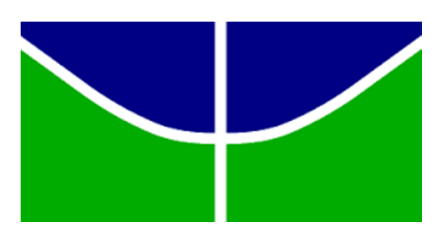

Universidade de Brasília

Faculdade de Economia, Administração e Contabilidade - FACE

Programa de Pós-Graduação em Administração - PPGA

FLÁVIO AUGUSTO MENDES SANTOS

\title{
A percepção das práticas de retenção de talentos em uma Instituição bancária nacional
}




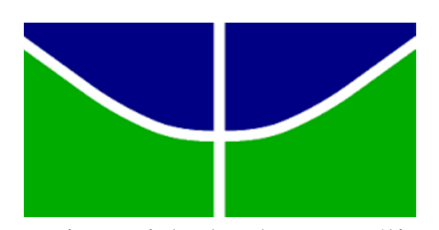

Universidade de Brasília

Faculdade de Economia, Administração e Contabilidade - FACE

Programa de Pós-Graduação em Administração - PPGA

\section{A percepção das práticas de retenção de talentos em uma Instituição bancária nacional}

FLÁVIO AUGUSTO MENDES SANTOS

Orientador: Prof. Dr. Francisco Antônio Coelho Junior

Dissertação de Mestrado

Brasília - DF

Março de 2017 
Santos, Flávio Augusto Mendes.

A PERCEPÇÃO DAS PRÁTICAS DE RETENÇÃO DE TALENTOS EM UMA INSTITUIÇÃO BANCÁRIA NACIONAL / Flávio Augusto Mendes Santos; orientador Francisco Antônio Coelho Júnior. - Brasília, 2017.

$67 \mathrm{p}$.

Dissertação (Mestrado- Mestrado em Administração) - Universidade de Brasília, 2015.

1. Retenção de Talentos. 2. Práticas Organizacionais de Retenção de Talentos. 3. Satisfação com o Trabalho. 4.Desempenho no Trabalho. I. Coelho Júnior, A. F., orient. II. Título 


\section{FLÁVIO AUGUSTO MENDES SANTOS}

\section{A percepção das práticas de retenção de talentos em uma Instituição bancária nacional}

Dissertação submetida ao Programa de PósGraduação em Administração (PPGA) da Universidade de Brasília como requisito parcial à obtenção do grau de Mestre em Administração.

Comissão Examinadora:

Prof. Dr. Francisco Antônio Coelho Junior, Universidade de Brasília Professor-Orientador

Prof $^{\mathrm{a}}$. Dr ${ }^{\mathrm{a}}$. Ana Cristina Limongi-França, Universidade de São Paulo Examinador Externo

Prof $^{\mathrm{a}}$. Dr ${ }^{\mathrm{a}}$. Tatiane Paschoal, Universidade de Brasília Examinador Interno

Prof. Dr. Rodrigo Rezende Ferreira, Universidade de Brasília Suplente

Brasília, 31 de março de 2017. 
O que prevemos raramente ocorre, o que menos esperamos geralmente acontece.

Benjamim Disraeli 


\section{Agradecimentos}

Aos meus pais, que mesmo na dificuldade, se esforçaram para me proporcionar o melhor. À minha irmã Camila, pela paciência e carinho.

À minha esposa Selma, que com sua forma peculiar de ser, me acompanhou em cada passo dessa jornada, mesmo desempenhando os papeis de Esposa, Mãe e Profissional.

Ao meu filho Benício, por me ensinar uma nova forma de superar os desafios da vida.

Ao meu orientador Francisco Coelho Jr., pelo incentivo e generosidade inigualáveis.

Às professoras Ana Cristina e Tatiane Paschoal por aceitarem participar desse processo.

Aos membros do Gepaco, em especial aos colegas Alan, Ladylucy Armond, Mariana Carolina e Natasha Fogaça pelo acolhimento e disponibilidade.

Ao amigo Felipe Guimarães Cortes, que com seu brilhantismo e determinação, me motivou a seguir em frente.

Ao professor Pedro Meneses por me ensinar o caminho correto a ser trilhado. 


\section{RESUMO}

A presente dissertação teve como objetivo geral verificar relações empíricas entre satisfação no trabalho, percepção da efetividade das práticas orientadas à retenção de talentos e autoavaliação de desempenho no âmbito de uma Instituição bancária nacional. Os objetivos específicos do estudo foram: (1) Apresentar evidências de validade interna da escala de percepção da efetividade das práticas de retenção de talentos; (2) Descrever a satisfação no trabalho junto a empregados de uma Instituição bancária nacional; (3) Descrever a percepção da efetividade das práticas orientadas à retenção de talentos junto a empregados de uma Instituição bancária nacional; (4) Descrever a percepção de autoavaliação de desempenho junto a empregados de uma Instituição bancária nacional; e (5) Testar os efeitos preditivos entre satisfação no trabalho, percepção da efetividade das práticas orientadas à retenção de talentos e autoavaliação de desempenho junto a colaboradores de uma Instituição bancária nacional. A amostra foi composta por 1.292 funcionários participantes de programas de qualificação organizados pela Empresa. Este total de funcionários era abarcado pelas políticas de retenção de talentos da Organização. Os resultados encontrados sugerem que há relação de predição entre retenção de talentos e desempenho - com destaque para os fatores atração e retenção e desempenho; foi confirmada a relação de predição entre satisfação no trabalho e desempenho, no que tange aos fatores engajamento com o trabalho e salários e oportunidades de crescimento. Além disso, os resultados indicaram que há relação entre características pessoais e profissionais e desempenho no trabalho. As implicações teóricas e práticas e as limitações do estudo são apresentadas, bem como uma agenda de pesquisa.

Palavras-chave: Retenção de Talentos; Desempenho; Satisfação; Instituição Bancária Nacional. 


\begin{abstract}
The purpose of this dissertation was to verify empirical relationships between job satisfaction, perception of the effectiveness of practices aimed at talent retention and self - evaluation of performance within a national banking institution. The specific objectives of the study were: (1) To present evidence of internal validity of the perception scale of the effectiveness of talent retention practices; (2) Describe job satisfaction with employees of a national banking institution; (3) Describe the perception of the effectiveness of practices aimed at retaining talents with employees of a national banking institution; (4) Describe the perception of selfevaluation of performance with employees of a national banking institution; And (5) Test the predictive effects between job satisfaction, perceived effectiveness of practices aimed at talent retention, and self-assessment of performance with employees of a national banking institution. The sample consisted of 1,292 employees participating in qualification programs organized by the Company. This number of employees was covered by the organization's talent retention policies. The results suggest that there is a prediction relationship between talent retention and performance - with emphasis on attraction and retention and performance factors; The prediction relationship between job satisfaction and performance was confirmed in relation to the factors of engagement with work and wages and growth opportunities. In addition, the results indicated that there is a relationship between personal and professional characteristics and performance at work. The theoretical and practical implications and limitations of the study are presented, as well as a research agenda.
\end{abstract}

Keywords: Retention of Talents; Performance; Satisfaction; National Banking Institution. 


\section{SUMÁRIO}

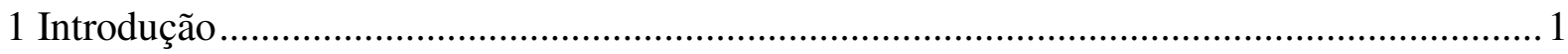

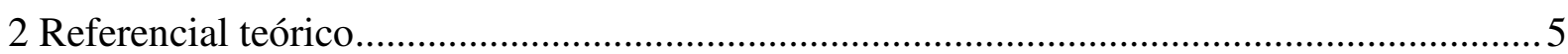

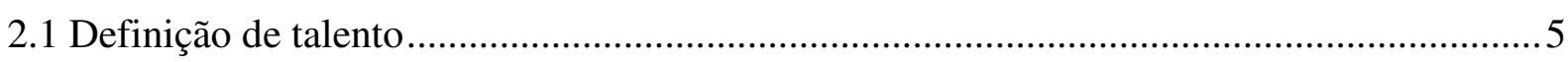

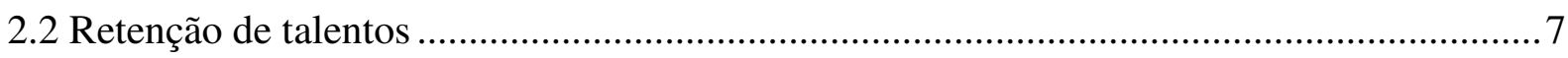

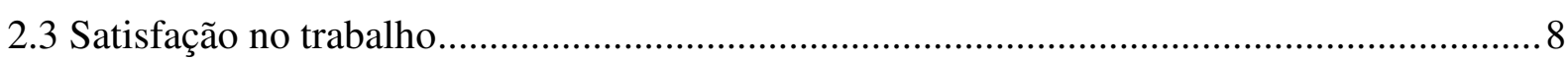

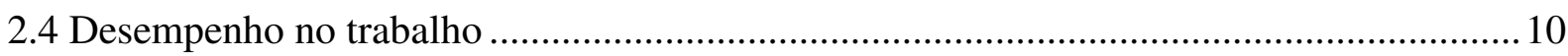

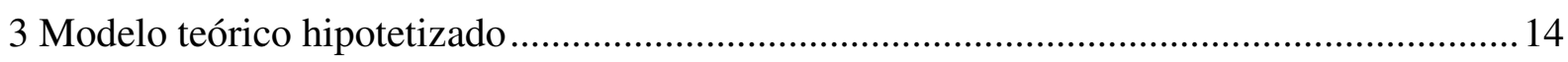

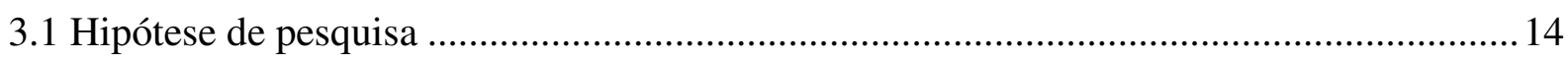

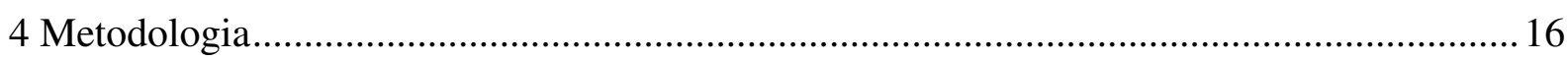

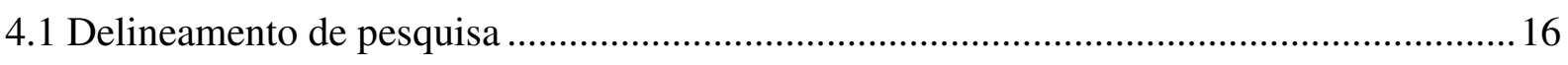

4.2 Caracterização da Organização em estudo .................................................................... 17

4.3 Caracterização dos instrumentos de pesquisa.............................................................. 17

4.4. Caracterização da população e amostra.......................................................................... 19

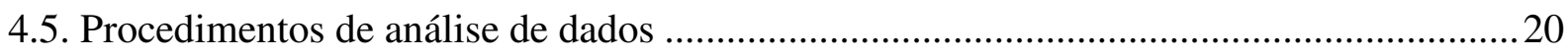

4.5.1 Análise fatorial e validações estatísticas ................................................................... 21

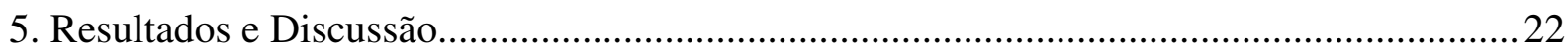

5.1. Resultados descritivos da escala de retenção de talentos ............................................... 22

5.2. Resultados descritivos da escala de autoavaliação de desempenho ................................. 24

5.3. Resultados descritivos da escala de satisfação no trabalho .............................................26

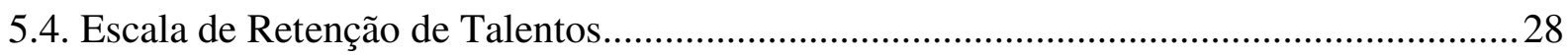

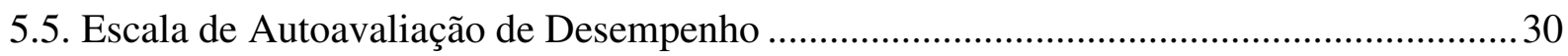

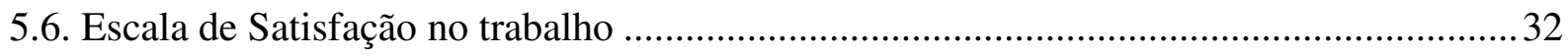

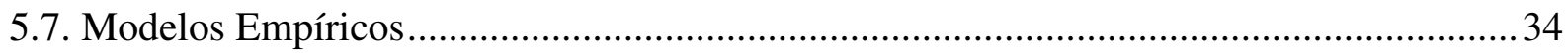

5.7.1 Variável Critério: Autogerenciamento de Desempenho.................................................. 36

5.7.2. Variável Critério: Execução, Monitoramento e Revisão de Desempenho .......................38

5.7.3 Variável Critério: Regulação de Desempenho ............................................................ 40

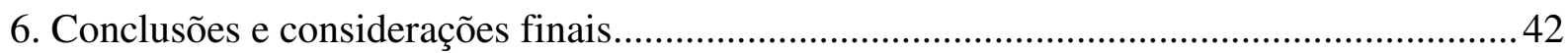

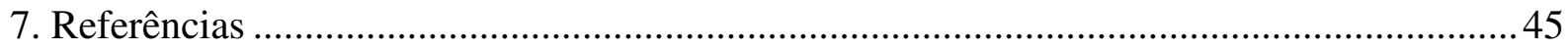

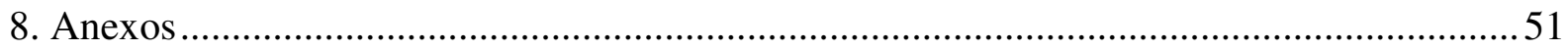

8.1 Medida de Autoavaliação de Desempenho no Trabalho ....................................................51

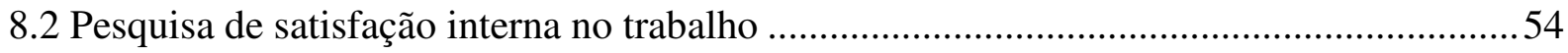

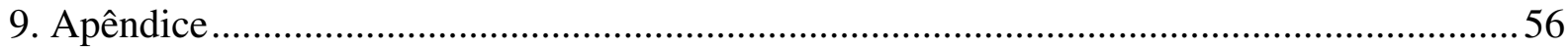

9.1 Percepção das Políticas e Práticas de Retenção de Talentos ...............................................56

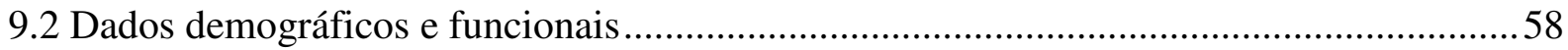




\section{Introdução}

Estimular o encarreiramento dos indivíduos vem sendo um importante desafio às áreas de recursos humanos nas organizações de trabalho. O desenvolvimento de práticas de recursos humanos (RH) que valorizem a presença humana no trabalho vem sendo incentivado, com vistas à promoção da satisfação com o trabalho, envolvimento e comprometimento.

Neste ínterim, as áreas de RH veem se tornando estratégicas para as organizações. Cada vez mais, ações táticas veem sendo incorporadas ao dia a dia das organizações, de forma a agregar valor ao capital intelectual e estimulando que os indivíduos evitem se evadir do trabalho. À esta nova perspectiva, em que se incentiva, de forma contínua, a presença humana no trabalho, Caracol, Palma, Lopes e Sousa (2016) denominam nova carreira organizacional.

Nos últimos anos tem-se verificado que a área de recursos humanos tem passado por diversas transformações. Essa nova identidade surgiu da necessidade das organizações de aumentarem a capacidade produtiva face à concorrência do mercado globalizado. Segundo Lacombe e Tonelli (2001), a partir dos anos 80, a gestão de pessoas assume um caráter estratégico de forma a integrar os objetivos de longo prazo da organização, as variáveis relevantes do ambiente e as necessidades decorrentes de pessoas.

Contratos psicológicos baseados na natureza relacional têm sido incentivados (Collins \& Mellahi, 2009) na promoção do encarreiramento dos indivíduos em situação de trabalho. Valorizando-se tal alinhamento a cultura organizacional é preservada, e os vínculos são fortemente estabelecidos (Clarke, 2013). Estimular e incentivar os indivíduos a permanecerem na organização por um longo período de tempo pode ser denominado como retenção de funcionários. É um processo no qual os funcionários são incentivados a permanecerem com a organização por um período máximo de tempo ou até a conclusão de um eventual projeto em que o mesmos se encontram inseridos (Denton, 2000).

No setor público, em consonância com essa transição da ARH (de meramente operacional para, de fato, estratégica às organizações), também ocorreu um movimento voltado para a administração estratégica de pessoas, baseado no New Public Management, originado especialmente na Europa e Estados Unidos. De acordo com Camões (2013), seguindo a tendência internacional, a administração pública brasileira realizou um movimento no sentido de modernizar e profissionalizar o serviço público tornando a gestão de pessoas uma ferramenta estratégica.

A nova administração pública, empenhada para trabalhar conforme o princípio da eficiência, de forma a atender aos anseios dos usuários-cidadãos, vem se tornando cada dia mais 
profissionalizada. A mão de obra vem se tornando mais qualificada, com um perfil complexo de competências, especialmente nos níveis gerenciais. No intuito de aumentar a produtividade, as organizações buscam ferramentas prescritivas como a gestão de desempenho, nos vários níveis organizacionais: institucional, de equipes e individual (OCDE, 2002). Além do mais, os gestores têm o desafio de manter os servidores motivados e comprometidos como o trabalho, a fim de mantê-los fidelizados a suas respectivas organizações (Das; Baruah, 2013).

Em face desse cenário, as organizações que mais se destacam são aquelas que, de fato, utilizam o fator humano como diferencial competitivo. Com isso, as organizações passaram a ter o desafio de garantir a permanência, em seus quadros, dos profissionais mais qualificados, os chamados talentos. Para Mendonça (2002), os talentos são profissionais que possuem competências de difícil aquisição e de importância estratégica para a competitividade, continuidade ou mesmo a sobrevivência de determinadas empresas.

Mendonça (2002), reconhece ainda que a valorização, o reconhecimento do desempenho e a adoção de recompensas colaboram para a retenção de talentos nas organizações. O novo paradigma de carreira baseia-se numa relação de reciprocidade entre empregador e empregados, em que existem responsabilidades partilhadas entre eles. Segundo levantamento dos temas emergentes na área de gestão de pessoas, realizado por da Silva Barreto, da Silva, Fischer, de Albuquerque e de Amorim (2011), a gestão de talentos torna-se uma tarefa ainda mais difícil em função da redução de fronteiras e o aumento da mobilidade da força de trabalho, influenciados pela globalização.

A retenção de talentos se dá nas esferas mental, social e física do trabalhador, segundo Osteraker (1999). A premissa básica da retenção de talentos refere-se à percepção de afiliação que este trabalhador tem em relação ao que ele acredita que a organização faz para mantê-lo trabalhando. São suas crenças em relação aos esforços organizacionais para mantê-lo dedicado e comprometido com o negócio organizacional (Milkovich; Newman, 2004).

Hausknecht, Rodda e Howard (2009) reconhecem que a possibilidade de crescimento interno, a melhoria salarial, a satisfação com o trabalho, a flexibilidade e a oferta de recompensas são mecanismos organizacionais utilizados como formas de reter talentos. Assim sendo, a manutenção dos profissionais com alto desempenho é fundamental para que as organizações consigam atingir suas metas e objetivos ao mesmo tempo que possibilita a criação de valor e proporciona a diferenciação frente aos demais concorrentes.

Nesse mesmo contexto, ganha importância a adoção de políticas e práticas de retenção de talentos pelas organizações públicas. A manutenção dos servidores que apresentam maiores níveis de comprometimento, satisfação e desempenho garante insumos essenciais para que as 
áreas de gestão de pessoas possuam o ferramental necessário para a melhoria dos serviços públicos. À medida que expectativas e necessidades individuais forem sendo atendidas, esperase que os indivíduos permaneçam mais tempo na organização, gerando-se um efeito ganhaganha (Ramlall, 2003; Wells; Thelen, 2002).

Assim considerado, torna-se importante identificar, sob a percepção dos colaboradores, qual é a sua ótica em relação a práticas de retenção de talentos que as organizações desenvolvem orientados à promoção da sua permanência e encarreiramento no trabalho. Analisando-se a literatura científica sobre o tema, como em Lewis e Heckman (2006) e Sullivam e Baruch (2009), pode-se derivar, teoricamente, que indivíduos que têm habilidades manifestadamente promovidas pelas organizações, por meio das práticas, e sentem-se valorizados/reconhecidos por isso provavelmente estarão mais felizes com o que fazem e terão melhor desempenho.

Isto posto, a presente Dissertação tem como objetivo geral verificar as relações empíricas preditivas entre satisfação no trabalho, percepção da efetividade das práticas orientadas à retenção de talentos e autoavaliação de desempenho no âmbito de uma Instituição bancária nacional.

A pergunta de pesquisa que norteia este trabalho é: quais relações empíricas preditivas podem ser estabelecidas entre satisfação no trabalho, percepção da efetividade das práticas orientadas à retenção de talentos e autoavaliação de desempenho junto a colaboradores de uma Instituição bancária nacional? Desta pergunta geral pode-se empreender outras questões de interesse: indivíduos mais satisfeitos com o seu trabalho perceberão de maneira mais positiva a política de gestão de talentos adotada pela Instituição? Quanto mais favorável a percepção da efetividade das práticas orientadas à retenção de talentos melhor o desempenho percebido? Que variáveis pessoais, tipificadas sob a forma de vínculo com o trabalho, como engajamento, poderão contribuir para a predição de desempenho?

A Empresa na qual o presente estudo foi desenvolvido possui uma área de recursos humanos organizada estrategicamente com o intuito de promover, dentre outros, programas de remuneração, benefícios e recompensas atrativos, oportunidades de ascensão baseadas na meritocracia e no desempenho individual, alinhados às necessidades organizacionais, ao mesmo tempo que promovem o desenvolvimento do corpo funcional. Além disso, em sua estratégia corporativa para o quinquênio 2017-2021, a organização assumiu o compromisso de promover o reconhecimento de talentos como forma de garantir a efetividade do seu processo sucessório.

Como objetivos específicos têm-se: 
(1) Apresentar evidências de validade interna da escala de percepção da efetividade das práticas de retenção de talentos;

(2) Descrever a satisfação no trabalho junto a empregados de uma Instituição bancária nacional;

(3) Descrever a percepção da efetividade das práticas orientadas à retenção de talentos junto a empregados de uma Instituição bancária nacional;

(4) Descrever a percepção de autoavaliação de desempenho junto a empregados de uma Instituição bancária nacional; e

(5) Testar os efeitos preditivos entre satisfação no trabalho, percepção da efetividade das práticas orientadas à retenção de talentos e autoavaliação de desempenho junto a colaboradores de uma Instituição bancária nacional.

Ressalta-se, como justificativa prática, que a oportunidade em realizar a pesquisa na Instituição em análise deveu-se ao aparente descontentamento dos funcionários em relação à política salarial e à falta de meritocracia nas ascensões internas apontadas na última pesquisa de satisfação, realizada em 2015. Espera-se que este estudo forneça insumos que possam permitir à ARH o realinhamento das ações que integram as práticas de retenção de talentos da Instituição estudada ao mensurar a percepção de um grupo de profissionais que são alvo das políticas e práticas de gestão de pessoas desenvolvidas pela Instituição. Importante salientar que esta pesquisa adotou, em seu escopo, o nível de análise individual.

A relevância teórica desta pesquisa está na contribuição que apresenta aos trabalhos empíricos na área de gestão de pessoas, sobretudo na investigação das práticas de retenção de talentos, tema ainda pouco explorado cientificamente no Brasil, mas bastante promissor para o desenvolvimento dos estudos organizacionais e comportamento organizacional. Este trabalho busca preencher a lacuna existente na literatura no que tange à relação empírica entre satisfação no trabalho, percepção das práticas de retenção de talentos e autoavaliação de desempenho no trabalho.

Neste Capítulo foi apresentada a introdução deste trabalho, que trouxe uma visão geral a respeito dos temas a serem discutidos. No próximo Capítulo serão apresentados os temas que compõem o referencial teórico e possibilitarão o atingimento dos objetivos propostos nesta dissertação. 


\section{Referencial teórico}

Neste Capítulo serão apresentados alguns trabalhos que tratam das práticas de retenção de talentos, satisfação com o trabalho e desempenho no trabalho. Para construção desta seção foram selecionados, por meio do Qualis/CAPES (B2 e acima) periódicos nacionais e internacionais nas áreas de Administração e Psicologia. Optou-se por privilegiar a literatura nacional sobre o tema "retenção de talentos", uma vez que o interesse de pesquisa sobre o mesmo, no Brasil, parece ser contemporâneo. Adotou-se como critério as publicações dos últimos 15 anos sobre o tema.

Em virtude da pequena quantidade de pesquisas nacionais que tratavam do tema retenção de talentos, decidiu-se por incluir algumas teses e dissertações sobre o tema. Além disso, é apresentada uma pesquisa bibliométrica da produção nacional e internacional de 2015, complementando os trabalhos desenvolvidos por Freitag (2012) e Mello (2014).

Esta Seção está dividida em quatro partes. Na primeira subseção serão apresentadas algumas definições de talento. Em seguida, serão descritas algumas práticas organizacionais de retenção de talentos. Nas duas últimas partes serão discutidas as influências que os construtos satisfação e desempenho no trabalho exercem sobre as práticas de retenção de talentos.

\subsection{Definição de talento}

No mundo organizacional, o termo talento, segundo Mendonça (2002), pode ser empregado aos colaboradores que possuem competências de difícil aquisição e que contribuem de forma direta para a estratégia empresarial. Para Michaels, Handfield e Axerold (2002) e Thunnissen, Boselie e Fruytier (2013), o talento diz respeito ao conjunto de habilidades individuais que compreendem os dons, o conhecimento, a experiência, a inteligência, além da capacidade de assumir desafios.

Ainda na antiguidade, a palavra "talento" fazia menção a medida de peso que, posteriormente, foi transformada em unidade monetária citada na Bíblia no livro de Mateus 25.14. No trecho, um homem distribui os talentos a seus servos em quantidades diferentes, segundo suas habilidades (Tansley, 2011; Gallardo-Gallardo; Dries; Gonzalez-Cruz, 2013). A partir desse fato, uma pessoa talentosa passou a ser reconhecida como alguém que possui habilidades diferenciadas, sejam inatas ou adquiridas por meio de dedicação ou treinamento. São muitas as definições de talentos encontradas na literatura (Brunetto; Farr-Wharton, 2002; Das; Baruah, 2013; Ulrich \& Smallwood, 2012). Iles, Chai e Preece (2010) citam como exemplo um levantamento organizado pela consultoria Towers Perrim, no ano de 2004, onde $87 \%$ das organizações pesquisadas possuíam uma definição para "talento". 
No entanto, as definições eram diferentes umas das outras, ou continham atributos ou dimensões diferenciadas sobre o termo. A Tabela 1 apresenta algumas definições encontradas na literatura.

Tabela 1

Definições do termo talento

\begin{tabular}{ll}
\hline \multicolumn{1}{c}{ Autores } & \multicolumn{1}{c}{ Definição } \\
\hline McClelland et al (1958) & $\begin{array}{l}\text { O termo talento é ambíguo. Em alguns momentos, se refere a } \\
\text { uma atitude ou habilidade pessoal, e às vezes ao desempenho } \\
\text { talentoso de um indivíduo, comportamento que vai além do } \\
\text { comum em atender algum critério desejável. }\end{array}$ \\
\hline Jackson e Schuler (1990) & $\begin{array}{l}\text { Pessoas que possuem ótima habilidade mental, que são } \\
\text { preparadas mentalmente para necessidades de inovação e } \\
\text { mudaça organizacionais. }\end{array}$ \\
\hline Fishman (1998) & $\begin{array}{l}\text { O recurso organizacional mais importante, ao longo dos } \\
\text { próximos 20 anos, será o talento. Pessoas de negócios, } \\
\text { inteligentes e sofisticadas, com conhecimento de tecnologia, }\end{array}$ \\
& $\begin{array}{l}\text { astutas e ágeis operacionalmente. Assim como a demanda por } \\
\text { eles cresce, a oferta irá cair. }\end{array}$ \\
\hline Berger e Berger (2004) & $\begin{array}{l}\text { Talento é a combinação de conjunto de habilidades, } \\
\text { competências e experiências necessárias à realização do } \\
\text { trabalho. }\end{array}$ \\
\hline Tlrich (2007) & $\begin{array}{l}\text { Talento é igual à competência vezes comprometimento vezes } \\
\text { contribuição. Empregados talentosos devem ter habilidades, } \\
\text { vontades e objetivos, além de serem capazes, comprometidos }\end{array}$ \\
\hline e contributivos. \\
\hline $\begin{array}{l}\text { Talentos são os trabalhadores que garantem a competitividade } \\
\text { e o futuro de uma organização, seja como líderes ou } \\
\text { especialistas, por meio de sua qualificação e conhecimento } \\
\text { específicos do trabalho, suas competências sociais e } \\
\text { metodológicas, como a vontade de aprender ou orientação para } \\
\text { resultados. }\end{array}$ \\
$\begin{array}{l}\text { Trabalhadores com potencial acima da média com base em seu } \\
\text { talento e realizam suas atividades muito bem. Além do que, } \\
\text { são dispostos e aptos a progredir. }\end{array}$ \\
\hline Everlim (2013)
\end{tabular}

Fonte: Adaptado de Freitag (2012) e Mello (2014)

Como pode ser visto, as diferentes compreensões para "talento" refletem as diferentes teorias que cercam esse termo. Meyers, Van Woerkom e Dries (2013) descrevem cinco abordagens sobre talento:

1) Talento como dom: o talento é percebido como uma habilidade inata. É uma visão exclusiva. Apenas são talentosos os indivíduos que nascem com um dom.

2) Talento como esforço: o talento é compreendido como resultado de uma habilidade adquirida mediante esforço e treinamento contínuos.

3) Talento como competência: o talento é visto como sendo resultado do conhecimento acrescido à habilidade inata. 
4) Talento como potencial: o talento é visto como algo a ser desenvolvido, uma característica pessoal que ainda não pode ser vista, mas que está latente.

5) Talento com resultado: o talento é distinguido a partir dos resultados entregues no presente. Um funcionário de alto desempenho que entrega bons resultados é considerado talentoso. Essa é uma visão pragmática e por diversas vezes adotada pelas organizações.

\subsection{Retenção de talentos}

Atualmente, um dos maiores desafios enfrentados pelas organizações é a retenção dos seus funcionários (especialmente aqueles mais qualificados), os chamados talentos. Na literatura (ver um conjunto delas em Iles, Preece \& Chuai, 2010) existem algumas definições sobre retenção. Bertnthal e Wellins (2001) a consideram como a habilidade organizacional de manter os empregados no lugar onde já se encontram.

Outros autores, como Ulrich (2000), acreditam que a retenção se trata de uma maneira de prender os colaboradores essenciais para o desempenho organizacional. Já Gayathri, Sivaraman e Kamalambal (2012) afirmam que a retenção dos empregados se refere às diversas práticas e políticas capazes de fazer com que os empregados fiquem "grudados" à organização por um longo período de tempo.

Para Kontoghiorges e Frangou (2009), retenção de pessoas é o resultado da satisfação mútua entre o empregado e seu empregador. A organização procura manter o funcionário satisfeito, cujas habilidades pessoais e profissionais servem a seus propósitos, enquanto que o funcionário procura continuar trabalhando em uma organização que atende a suas necessidades (Hilthrop, 1999).

Um ponto importante a ser considerado é a distinção entre retenção de pessoas e rotatividade. Steil, Penha e Bonilha (2016) constataram que retenção de pessoas e rotatividade não podem ser considerados opostos. Segundo os autores, a retenção representa uma capacidade organizacional para manter os empregados considerados importante nas organizações, enquanto que a rotatividade especifica o percentual de saída dos funcionários de uma organização em determinado período de tempo.

$\mathrm{Na}$ literatura poucos estudos se preocuparam em analisar os fatores que levam os empregados a permanecerem nas organizações (Allen; Bryant; Vardaman, 2010; Cardy; Lengnick-Hall, 2011; Dipietro; Thozhur. Milman, 2007). Por essa razão, os fatores de retenção ainda não são plenamente compreendidos pelos profissionais de Recursos Humanos. Bertnthal e Wellins, (2001) afirmam que a partir do entendimento desses fatores, poderão surgir novas 
abordagens que auxiliarão as organizações na solução dos problemas ligados à retenção de pessoas.

Nessa abordagem, um dos trabalhos mais destacados foi o desenvolvido por Hausknecht et al. (2009) em que as dimensões de retenção podem variar de acordo com o grau de satisfação ou nível de desempenho no cargo ou função. Esse estudo foi desenvolvido nos Estados Unidos, em uma organização do ramo de lazer hotelaria, englobando cerca de 24 mil empregados em 21 estados americanos.

\subsection{Satisfação no trabalho}

Satisfação no trabalho é um assunto que tem chamado a atenção dos pesquisadores em estudos organizacionais e de modo especial dos gestores desde os primeiros anos do século XX. Para Martinez (2002), a variável satisfação era relacionada à motivação, tendo, portanto, ligação com as teorias relacionadas ao comportamento no trabalho, como a teoria das necessidades de Maslow (1970), a teoria X e Y (1960) e a teoria dos fatores de Herzeberg, Mausner e Snyderman, (1959).

Por meio desse cenário, Siqueira (1995) advoga que os administradores começaram a defender o tema satisfação como causa de comportamentos de seus colaboradores, refletindo, assim, em indicadores de desempenho, produtividade, rotatividade e absenteísmo. Ainda segundo a autora, a partir dos anos 80 , a satisfação passou a ser encarada com atitude, detentora de componentes afetivos e cognitivos, capaz de predizer diversos comportamentos no trabalho.

Mesmo com o empenho dos pesquisadores, não há consenso a respeito da definição e natureza do construto satisfação no trabalho. De acordo com Marinho (1988), há uma forte tendência em ligar o construto de acordo com a natureza afetiva, ainda que o autor vislumbre um traço disposicional.

Já no século XXI, satisfação é vislumbrada como uma das variáveis que estão relacionadas à afetividade no trabalho. Siqueira (2008) determina o enfoque do construto como sendo o resultado do ambiente organizacional sobre a saúde do trabalhador. Para a autora, a satisfação pode ser apontada com um dos três componentes psicossociais do conceito de bemestar no trabalho e com o comprometimento organizacional afetivo.

Siqueira e Gomide Júnior (2004) expõem que, quanto à dimensionalidade, a satisfação pode ser considerada com um conjunto de reações específicas a componentes do trabalho, capazes de desencadear no indivíduo diferentes níveis de satisfação/insatisfação (visão multidimensional). Ainda conforme essa visão, diferentes aspectos do trabalho são 
considerados como fontes de satisfação no trabalho, sendo os mais frequentes os fatores ligados à chefia, colegas de trabalho, o próprio trabalho, salário e oportunidades de promoção.

Enquanto chefia e colegas de trabalho estão ligados às dimensões relativas ao ambiente social, o próprio trabalho representa as atividades laborativas. Salário e oportunidades de promoção são aspectos da gestão de pessoas através das quais as organizações manifestam sua retribuição aos empregados, constituindo-se em duas formas do colaborador observar os resultados advindos de seus investimentos na organização e avaliar sua relação de troca com esta.

Para Tamayo (2000), o grau de satisfação com o trabalho é resultado da coincidência entre o que um indivíduo procura no seu trabalho com o que realmente se retira dele. Quanto maior a diferença entre o que o empregado espera conseguir no trabalho e o que realmente ele obtém, menor é a satisfação no trabalho.

Muitos autores chamam atenção para a relação entre satisfação e retenção de pessoas. Nessa perspectiva, um dos primeiros trabalhos a se destacar foi o desenvolvido por March e Simon (1958). Nessa pesquisa, os autores afirmam que o desejo de movimentação dos trabalhadores era um elemento essencial do processo de turnover e que estaria ligado ao nível de satisfação ou insatisfação com o trabalho.

Dentro dessa perspectiva, Riza, Ganzach e Liu (2016) desenvolveram um modelo que contou com a participação de 21.670 trabalhadores norte-americanos que confirmou a existência de uma relação negativa entre satisfação no trabalho e tempo de serviço. A medida que se aumentava o tempo de serviço na mesma organização, o nível de satisfação dos trabalhadores diminuía. Em compensação, a medida que os indivíduos mudavam de uma organização para outra, sua satisfação no trabalho aumentava.

A Tabela 2 apresenta outros autores que se dedicaram a pesquisar a relação entre satisfação com o trabalho e retenção de pessoas ou turnover.

Tabela 2

Estudos sobre satisfação no trabalho

\begin{tabular}{ll}
\hline \multicolumn{1}{c}{ Autores } & \multicolumn{1}{c}{ Definição } \\
\hline Hulim e Smith (1965) & $\begin{array}{l}\text { Em pesquisa com empregados de uma organização } \\
\text { americana de eletrônicos, os autores observaram que há } \\
\text { correlação ente a satisfação com o trabalho e o tempo de } \\
\text { organização. }\end{array}$ \\
\hline Porter e Steers (1973) & $\begin{array}{l}\text { Em artigo que analisou vários estudos sobre turnover nas } \\
\text { décadas de 60 e 70, demonstraram que a maioria dos } \\
\text { estudos concluiu que a satisfação com o conteúdo do } \\
\text { trabalho tem uma relação negativa com turnover. }\end{array}$ \\
\hline
\end{tabular}




\begin{tabular}{ll}
\hline Gaertner e Nollen (1992) & $\begin{array}{l}\text { A satisfação com o trabalho é um dos principais elementos } \\
\text { diferenciadores entre os empregados que têm a intenção de } \\
\text { permanecer na organização e aqueles que tem a intenção de } \\
\text { deixá-la. }\end{array}$ \\
\hline Griffeth, Hom e Gaertner (2000) & $\begin{array}{l}\text { Assim com Gaertner e Nollen (1992), concluíram em } \\
\text { pesquisa de meta-análise, que a satisfação com o trabalho } \\
\text { tem forte relação negativa com turnover, sendo } \\
\text { considerada uma variável preditiva para análise da saída de } \\
\text { empregados. }\end{array}$ \\
\hline Ramesh e Gelfand (2010) & $\begin{array}{l}\text { Em pesquisa intercultural desenvolvida entre Estados } \\
\text { Unidos e Índia, em uma empresa de call center, os autores } \\
\text { encontraram relação negativa entre satisfação com trabalho } \\
\text { e turnover, nos dois países analisados. }\end{array}$ \\
\hline
\end{tabular}

Fonte: Adaptado de Freitag (2012) e Mello (2014)

\subsection{Desempenho no trabalho}

Desempenho no trabalho é um assunto de grande importância prática e acadêmica. Campbell (1990) foi o primeiro estudioso a propor um modelo, sendo um dos mais citados na literatura. Para o autor, desempenho pode ser definido como um comportamento ou ação significativa para o atingimento dos objetivos organizacionais e podendo ser medido a partir da margem de contribuição para tais objetivos.

Para Lucena (1992), o desempenho no trabalho pode ser compreendido como a atuação do empregado em função do cargo por ele ocupado na organização, cujo conteúdo específico compreende as responsabilidades, tarefas e desafios a ele atribuídos.

Sonnentag e Frese (2002) afirmam que o conceito de desempenho no trabalho pode envolver comportamentos e resultados. Para esses autores, comportamentos referem-se a ações executadas pelo indivíduo, isto é, aquilo que o empregado faz em uma situação de trabalho, enquanto resultados representam consequências do comportamento adotado.

Para Coelho Júnior (2009), o desempenho refere-se a um conceito de natureza dinâmica, em que estão inseridos uma série de variáveis que, de forma isolada ou conjunta, são capazes de predizer sua variância no trabalho. Além disso, o autor propõe uma diferenciação entre os níveis de desempenho. O desempenho competente refere-se aos tipos de conhecimentos e habilidades que um indivíduo utiliza para a consecução de seus planos de trabalho e que devem estar alinhados às necessidades da organização. Em contrapartida, o desempenho considerado incompetente refere-se à sorte de comportamentos expressos pelo indivíduo e que estão aquém do que é exigido pela organização.

Bendassoli (2012) apresenta outros modelos teóricos de grande relevância na literatura científica sobre desempenho, conforme se observa na Tabela Y: 
Tabela 3

Modelos teóricos de desempenho

\begin{tabular}{|c|c|c|}
\hline Autores & Proposta & Principais elementos \\
\hline $\begin{array}{l}\text { Borman \& } \\
\text { Motowidlo } \\
(1993)\end{array}$ & $\begin{array}{l}\text { Desempenho } \\
\text { como conceito } \\
\text { multidimensional }\end{array}$ & $\begin{array}{l}\text { Desempenho de tarefa: } \\
\text { - Contribuição para o core técnico do cargo } \\
\text { Desempenho contextual: } \\
\text { - Persistência e esforço na realização das } \\
\text { tarefas } \\
\text { - Realizar tarefas voluntariamente, extra- } \\
\text { - } \text { papel } \\
\text { - Ajudar e cooperar com os outros } \\
\text { - Apoiar de defender os objetivos } \\
\text { organizacionais }\end{array}$ \\
\hline $\begin{array}{l}\text { Murphy (1989a; } \\
\text { 1989b) }\end{array}$ & $\begin{array}{l}\text { Desempenho } \\
\text { como conceito } \\
\text { dinâmico e } \\
\text { multidimensional }\end{array}$ & $\begin{array}{l}\text { Importância das habilidades e de variáveis } \\
\text { disposicionais como causas do desempenho variam } \\
\text { em dois estágios: } \\
\text { - Estágio de transição; } \\
\text { - Estágio de manutenção } \\
\text { As dimensões são: } \\
\text { - Comportamentos orientados para a tarefa } \\
\text { - Comportamentos interpessoais } \\
\text { - Comportamentos de indisponibilidade } \\
\text { - Comportamentos destrutivos }\end{array}$ \\
\hline $\begin{array}{l}\text { Frese \& Zapf; } \\
\text { Frese \& Fay } \\
\text { (2001) e } \\
\text { Sonnentag (1998) }\end{array}$ & Desempenho ativo & $\begin{array}{l}\text { Desempenho é visto como um processo de ação } \\
\text { regulado na seguinte sequência: } \\
\text { - Estabelecimento de objetivos; } \\
\text { - Busca de informação; } \\
\text { - Planejamento; } \\
\text { - Monitoramento; } \\
\text { - Feedback } \\
\text { O desempenho ativo é resultado de ações } \\
\text { disparadas por iniciativa pessoal e composta por } \\
\text { três facetas: } \\
\text { - Auto iniciativa } \\
\text { - Proatividade } \\
\text { - Persistência }\end{array}$ \\
\hline $\begin{array}{l}\text { Pulakos et.al. } \\
\text { (2000); Pulakos } \\
\text { et.al. (2002); } \\
\text { Griffin, Neal \& } \\
\text { Parker (2007) } \\
\text { Sonnentag et.al. } \\
\text { (2008) }\end{array}$ & $\begin{array}{l}\text { Desempenho } \\
\text { adaptativo }\end{array}$ & $\begin{array}{l}\text { O desempenho é uma ação situacional e adaptativa } \\
\text { em oito dimensões: } \\
\text { - Lidar com situações de crise } \\
\text { - Lidar com o stress no trabalho } \\
\text { - Resolver problemas criativamente } \\
\text { - Lidar com situações incertas ou } \\
\text { imprevisíveis } \\
\text { - Aprender tarefas, tecnologias e } \\
\text { - } \text { procedimentos relacionados ao trabalho } \\
\text { - Demonstrar adaptabilidade interpessoal } \\
\text { - Demonstrar adaptabilidade cultural }\end{array}$ \\
\hline
\end{tabular}




\section{Conclusão}

\begin{tabular}{|c|c|c|}
\hline $\begin{array}{l}\text { Beal, Weiss, } \\
\text { Barros \& } \\
\text { MacDermid } \\
\text { (2005) }\end{array}$ & $\begin{array}{l}\text { Desempenho } \\
\text { episódico }\end{array}$ & $\begin{array}{l}\text { Episódios de desempenho são segmentos } \\
\text { compartimentais que são tematicamente } \\
\text { organizados em torno de objetivos ou metas } \\
\text { organizacionais relevantes. O processo envolve seis } \\
\text { aspectos: } \\
\text { - Nível de recursos cognitivos e sua alocação } \\
\text { - Demandas de atenção não relacionadas à } \\
\text { tarefa } \\
\text { - Auto regulação da atenção } \\
\text { - Regulação de recursos } \\
\text { - Tração de tarefas com efeitos na atenção } \\
\text { objeto individual na tarefa ou em outro }\end{array}$ \\
\hline
\end{tabular}

Fonte: Bendassoli (2012), com adaptações

Levantamento bibliográfico realizado por Fogaça, Rego e Armond (2016), aponta que o desempenho ainda é estudado como variável dependente, de acordo com os estudos de Sonnentag e Frese (2002). Segundo as autoras, tal escolha caracteriza a prevalência de aspectos econômicos, como a contribuição individual dos trabalhadores para o atingimento das metas organizacionais.

O desempenho, no que diz respeito às práticas de retenção de talentos, torna-se essencial para a sobrevivência das organizações. Aldamoe, Yazam e Ahmid (2011) afirmam que a retenção de empregados de alto desempenho, os chamados talentos, é um dos elementos fundamentais para conexão entre as práticas de gestão de pessoas e o desempenho organizacional. Na mesma linha Talentdrain (2008), afirma que práticas de retenção bem aplicadas representam ganho de eficiência organizacional, ao reduzir custos de recrutamentos e consequentemente aumentar os níveis de motivação e desempenho do corpo funcional.

Na esfera pública, a situação não é diferente. Moynihan e Pandey (2010) comprovaram que o déficit de desempenho foi o principal motivo para a realização de reformas administrativas em diversos países. Para esses autores, a partir da necessidade de prestação de contas e do avanço da tecnologia, os atores governamentais (cidadãos, políticos e gestores), passaram a ter livre acesso aos dados de desempenho.

Por essa razão, aumenta-se a procura por sistemas de avaliação de desempenho pelas organizações públicas. Em função da busca por maior produtividade, os órgãos públicos passam a adotar ferramentas prescritivas para controle dos níveis de desempenho, sejam organizacionais, de equipe ou individuais (OCDE, 2002).

A partir desse panorama, Hsieh (2016) estudou as semelhanças e diferenças entre trabalhadores chineses oriundos das três esferas (pública, privada e sem fins lucrativos) em 
relação aos níveis de desempenho e satisfação no trabalho. Os resultados, analisados por meio de técnicas estatísticas, mostraram que o desempenho está positivamente relacionado à satisfação no trabalho e vice-versa.

Neste Capítulo foram abordados a literatura que auxiliará no atingimento dos objetivos propostos nesta dissertação. Entre os temas apresentados estão a definição de talentos, a importância das práticas organizacionais de retenção de talentos, assim como satisfação com o trabalho e desempenho no trabalho. No próximo capítulo será formulada a hipótese que norteará o modelo teórico hipotetizado. 


\section{Modelo teórico hipotetizado}

A presente pesquisa está fundamentada na pesquisa desenvolvida por Mello (2014). Em suas considerações sobre estudos futuros, o autor sugere que sejam abordados trabalhos mais focados em determinado fator de retenção ou característica do empregado e por meio de técnicas quantitativas verificar o quanto determinado construto afeta o fator de retenção.

\subsection{Hipótese de pesquisa}

A construção da hipótese a ser testada neste trabalho foi baseada nas preposições de Mello (2014) e Hausknecht et al. (2009), considerando a quantidade de variáveis envolvidas e as relações estabelecidas entre elas e a percepção das práticas organizacionais voltadas à retenção de talentos.

Em sua pesquisa, Hausknecht et al. (2009) realizaram levantamento junto aos empregados de uma organização norte americana que atua nos setores de hotelaria e lazer, abrangendo mais de 24 mil empregados em 21 estados americanos.

Tal levantamento enumerou doze fatores informados pelos funcionários como motivos para permanência nas organizações. São eles: satisfação no trabalho, recompensas extrínsecas, oportunidades de desenvolvimento, relacionamentos, investimento, comprometimento organizacional, justiça organizacional, flexibilidade no trabalho, prestígio organizacional, localização, influências não relacionadas ao trabalho e falta de alternativas.

Mello (2014) afirma que ao contrário dos estudos anteriores, que focavam as práticas de gestão de pessoas voltadas para a manutenção dos colaboradores, ou nos motivos que levam os desligamentos dos funcionários os Hausknecht et. al. (2009) focaram na perspectiva dos empregados para explicar seus motivos para permanência nas organizações.

A oportunidade em realizar a pesquisa na Instituição em análise surgiu a partir de relatos informais ao pesquisador de que não havia meritocracia nas ascensões internas. Empregados com distinto tempo de serviço, e em diferentes ocupações hierárquicas, parecem estar insatisfeitos com condições laborais promovidas pela Organização em estudo.

As pessoas pareciam compartilhar crenças negativas acerca de práticas organizacionais internas por mais que tenham observado uma preocupação dos gestores organizacionais em investirem maciçamente nas práticas de retenção. Com base nestas considerações, foi elencada a seguinte hipótese de pesquisa:

H1: Variáveis pessoais (idade e escolaridade), profissionais (nível de cargo e tempo de serviço), satisfação no trabalho e percepção de efetividade das práticas orientadas à retenção de talentos predirão positivamente autoavaliação de desempenho no trabalho. 
Para a melhor compreensão do estudo proposto foi desenvolvido um modelo teórico hipotetizado de pesquisa, representado graficamente na Figura 1.

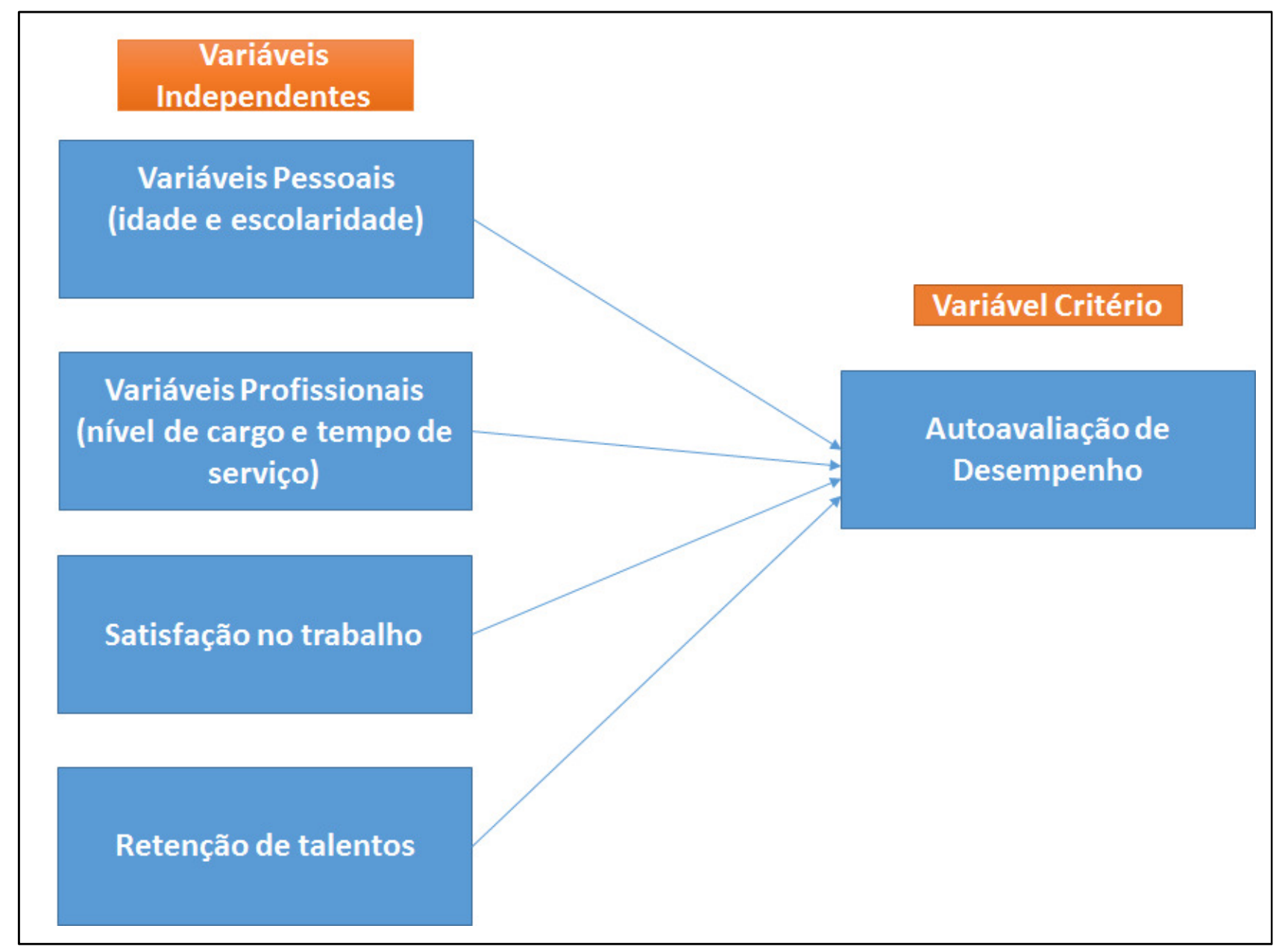

Figura 01. Modelo teórico hipotético Fonte: Elaborado pelo autor

No próximo Capítulo apresentam-se os procedimentos metodológicos adotados para o presente estudo. É apresentado o delineamento de pesquisa, bem como os procedimentos de coleta e análise de dados e o perfil amostral obtido. 


\section{Metodologia}

Este Capítulo apresenta os procedimentos metodológicos adotados visando atingir os objetivos de pesquisa propostos. Na primeira parte serão apresentados o tipo e descrição geral da pesquisa. Em seguida é apresentada a Organização estudada juntamente com o instrumento de pesquisa e, ao final, são descritos os procedimentos de coleta de análise de dados.

\subsection{Delineamento de pesquisa}

Esta pesquisa procurou investigar, de forma empírica, as variáveis relacionadas à percepção da efetividade das práticas orientadas à retenção de talentos no lócus de uma Instituição bancária nacional.

Esta pesquisa pode ser caracterizada como sendo de caráter descritivo/exploratório, com delineamento explicativo. Exploratório, ao estudar um assunto pouco explorado, ou mesmo analisá-lo sob novos pontos de vista; descritivo, visto que tem a finalidade de descrever uma situação ou a manifestação de um fenômeno; e explicativo, por estabelecer relações preditivas não causais entre acontecimentos, fatos ou fenômenos estudados (Sampieri, Collado \& Lúcio 2006). Além disso, este trabalho tem caráter temporal transversal, pois as informações serão coletadas em um momento específico da realidade.

Foram utilizados dados primários (instrumentos de política de retenção de talentos e autoavaliação de desempenho) e secundários (instrumento de satisfação com o trabalho desenvolvido pela Organização). A utilização de dados secundários permitiu com que se utilizassem informações que a própria Organização já havia coletado anteriormente. Estes dados foram tratados estatisticamente (especialmente com vistas à identificação de possíveis casos em branco, erros de digitação ou vieses de preenchimento das planilhas fornecidas pela Organização), de modo a servirem de base para o estudo empírico. Todo o cuidado com o tratamento destes dados foi tomado.

Quanto à natureza, esta pesquisa pode ser classificada como quantitativa, pois foram coletados dados junto a um grupo de empregados por meio da utilização da técnica de levantamento ou survey (por meio de questionário totalmente estruturado). Esta modalidade de pesquisa busca traduzir opiniões e informações em números para posterior classificação e análise. O método de análise de dados empregado foi o método estatístico. 


\subsection{Caracterização da Organização em estudo}

A Instituição foi fundada em 12/10/1808 por D. João VI, quando da instalação da coroa portuguesa no Rio de Janeiro, em virtude da invasão francesa ao território português.

A Organização se caracteriza por ser uma sociedade de economia mista, com ações negociadas em bolsa de valores. O seu maior acionista é o Tesouro Nacional com 50,73\% do capital, seguido pela Caixa de Previdência dos Funcionários da Organização (Previ) que detém 9,97\% de participação acionária, Fundo Fiscal de Investimento e Estabilização com 3,67\% e 2,81\% no formato de ações em tesouraria, distribuídas no mercado.

Até o ano de 1986, detinha a conta movimento do Banco Central e Tesouro Nacional, o que lhe garantia o status de autoridade monetária. Nos dias atuais, sua atuação é de banco múltiplo com estrutura de conglomerado, com entidades ligadas que atuam nas áreas de saúde, capitalização, previdência, cartão de crédito, consórcio e informática. Além disso, a Organização possui uma Fundação, responsável por atividades sociais junto às comunidades carentes espalhadas por todo o país.

Atualmente, a Organização possui cerca de 115.000 funcionários distribuídos em unidades estratégicas, táticas, negociais e de apoio à gestão. Ela se faz presente em mais de 5.000 agências, espalhadas por 3.566 municípios brasileiros, e conta com cerca de 57.000 terminais eletrônicos localizados em quiosques, shoppings, aeroportos, rodoviárias. Além disso, dispõe de 50 pontos de atendimento no exterior, localizados em 40 países, distribuídos na forma de agências, escritórios e subsidiárias. Nos últimos tempos, como forma de acompanhar as tendências do mercado financeiro, a Organização tem investido em plataformas digitais, que possibilitam a realização de negócios e prestação de serviços em horários diferenciados, se comparados ao funcionamento oferecido pelas agências bancárias.

\subsection{Caracterização dos instrumentos de pesquisa}

Para realização do presente trabalho foram utilizados três instrumentos de pesquisa. $\mathrm{O}$ primeiro instrumento mensurou a percepção das práticas de retenção de talentos, sendo composto por 25 itens no formato da escala composta por 10 pontos, onde 1 correspondia a "Discordo totalmente" e 10 correspondia a "Concordo totalmente".

Os itens que compuseram a versão inicial do instrumento foram extraídos da literatura científica sobre dimensões de retenção de talentos nas organizações. A partir da identificação das principais categorias de práticas organizacionais orientadas à retenção de talentos elaborouse uma primeira redação dos itens, contando com as recomendações dadas por Pasquali (2002). 
Além da contribuição teórica para a formulação de itens, foram consideradas, também, as práticas organizacionais de retenção de talentos que a própria Organização havia instituído. Desta forma, aliou-se este critério empírico ao critério teórico para uma primeira formulação de itens, para fins de validação por juízes e semântica ulteriores.

Após a primeira versão inicial dos itens procedeu-se à validação por juízes junto a 5 professores dos Departamentos de Administração e Gestão de Políticas Públicas da Universidade de Brasília. Ainda, a fim de garantir validade externa à medida, procedeu-se à validação de juízes de profissionais da ARH da Organização em análise.

Após esta validação inicial ainda foram tomadas providências necessárias para eliminar possíveis ambiguidades e vieses nas questões do instrumento adotado. Foi feita uma primeira validação semântica junto a empregados da Organização em estudo.

Após a validação por juízes e a primeira validação semântica na Organização, o questionário foi respondido e criticado pelos membros do Grupo de Estudos Avançados em Comportamento Organizacional (Gepaco), da Universidade de Brasília (UnB), visando o aperfeiçoamento do mesmo. Antes de sua aplicação à toda população esperada, o instrumento passou ainda por nova validação semântica junto a empregados que fazem parte da Organização estudada, no sentido de dirimir quaisquer eventuais erros de interpretação ou vieses na redação dos itens (clareza, pertinência e precisão da redação).

O segundo instrumento, Medida de Autoavaliação de Desempenho no Trabalho, foi construído e validado empiricamente por Coelho Jr., Borges-Andrade, Oliveira e Pereira (2010). Esse questionário foi composto por 27 itens, divididos em quatro fatores, a saber: regulação do desempenho, com 12 itens; grau de esforço e conhecimento da tarefa, com três itens; execução, monitoramento e revisão do desempenho, com quatro itens, e; autogerenciamento do desempenho com oito itens. Os itens foram associados à escala tipo Likert, composta por 10 pontos, onde 1 correspondia a "Discordo totalmente" e 10 correspondia a "Concordo totalmente".

O terceiro instrumento foi baseado na pesquisa de satisfação interna no trabalho, aplicada pela própria Instituição, construída e validada empiricamente por Valle (2009). Esse questionário foi composto por 16 itens, divididos em dois fatores, a saber: engajamento com o trabalho, composto por 11 itens; salário e oportunidades de crescimento, com cinco itens. Da mesma forma que os demais instrumentos, os itens foram associados a uma escala tipo Likert composta por 10 pontos, onde 1 correspondia a "Discordo totalmente" e 10 correspondia a "Concordo totalmente". Ressalta-se que estes foram os procedimentos que Valle (2009) utilizou, de maneira que estes dados foram apropriados como dados secundários visando pareá- 
los com os dados primários relativos à percepção de efetividade das práticas de retenção e talentos e a autoavaliação de desempenho.

\subsection{Caracterização da população e amostra}

A população alvo do estudo foi constituída por 5.806 funcionários participantes de programas de qualificação organizados pela Empresa. Este total de funcionários era abarcado pelas políticas de retenção de talentos da Organização. Nem todos os funcionários (terceirizados, por exemplo) eram objeto das práticas, e foram descartados para composição da amostragem.

Os questionários foram encaminhados aos 5.806 possíveis participantes, via e-mail corporativo, com o auxílio do aplicativo Limesurvey. Os instrumentos ficaram disponíveis online por 30 dias, no período compreendido entre 20 de setembro e 20 de outubro de 2016 . Ao final foram coletadas 1.292 respostas, amostra inicial deste estudo.

Conforme sugerido por Tabachnick e Fidell (2007) e Hair, Black, Babin, Anderson e Tatham (2006), quanto maior o número e a diversidade da amostra será melhor, desde que a amostra supere 50 observações, sendo recomendado um mínimo de 100 casos por construto/variável para fins de se assegurar resultados mais consistentes e externamente válidos. A partir disso, conclui-se que os requisitos quanto à quantidade mínima de participantes foram atendidos.

Por fim, considerou-se também o critério de significância estatística (p). Este cálculo foi feito através do software Raosoft. Pelo critério de significância recomendou-se uma amostra mínima de 596 participantes, com intervalo de confiança de 99\%. A amostra obtida atendeu aos requisitos expostos.

Quanto ao perfil dos participantes desta pesquisa, identificou-se que a grande maioria está na faixa etária compreendida entre 30 e 50 anos (84,8\%), sendo 67,5\% do sexo masculino com tempo de banco entre 10 e 20 anos $(81,8 \%)$. O nível de escolaridade obtido foi pósgraduação latu sensu $(90,4 \%)$ e exercendo função gerencial $(65,8 \%)$.

Tais características demonstram que os participantes dos processos de qualificação da empresa são pessoas maduras e que detêm nível de formação elevado em comparação à maioria da população brasileira. Os dados encontram-se sintetizados na Tabela 4. 
Tabela 4

Perfil Amostral

\begin{tabular}{|c|c|c|}
\hline Variável & Frequência & $\%$ \\
\hline \multicolumn{3}{|l|}{ Idade } \\
\hline Até 30 anos & 45 & $3,5 \%$ \\
\hline Entre 30 e 40 anos & 694 & $53,7 \%$ \\
\hline Entre 41 e 50 anos & 402 & $31,1 \%$ \\
\hline Entre 51 e 60 anos & 149 & $11,5 \%$ \\
\hline Acima de 60 anos & 2 & $0,2 \%$ \\
\hline Variável & Frequência & $\%$ \\
\hline \multicolumn{3}{|l|}{ Tempo de Banco } \\
\hline Até 10 anos & 315 & $24,4 \%$ \\
\hline Até 20 anos & 742 & $57,4 \%$ \\
\hline Até 30 anos & 180 & $13,9 \%$ \\
\hline Acima de 30 anos & 55 & $4,3 \%$ \\
\hline \multicolumn{3}{|l|}{ Gênero } \\
\hline Masculino & 872 & $67,5 \%$ \\
\hline Feminino & 420 & $32,5 \%$ \\
\hline \multicolumn{3}{|l|}{ Escolaridade } \\
\hline Médio & 3 & $0,2 \%$ \\
\hline Superior em Andamento & 3 & $0,2 \%$ \\
\hline Superior & 79 & $6,1 \%$ \\
\hline Especialização & 1168 & $90,4 \%$ \\
\hline Mestrado & 38 & $2,9 \%$ \\
\hline Doutorado & 1 & $0,1 \%$ \\
\hline \multicolumn{3}{|l|}{ Função } \\
\hline Técnicos & 35 & $2,7 \%$ \\
\hline Assessores & 176 & $13,6 \%$ \\
\hline Auditores & 12 & $0,9 \%$ \\
\hline Gerentes & 850 & $65,8 \%$ \\
\hline Primeiros Gestores & 193 & $14,9 \%$ \\
\hline Superintendentes & 21 & $1,6 \%$ \\
\hline Executivos & 5 & $0,4 \%$ \\
\hline
\end{tabular}

Fonte: Dados da pesquisa

\subsection{Procedimentos de análise de dados}

Os dados foram analisados por meio de estatística inferencial. No primeiro momento, foram feitos os cálculos das médias, distribuição de frequências, análise fatorial exploratória, correlações e regressões. As análises estatísticas foram realizadas com o auxílio da ferramenta SPSS - Statistical Package for Social Sciences, versão 20.

Nas análises exploratórias iniciais foram tomados cuidados quanto à identificação dos casos extremos (outliers). Usando a distância Mahalanobis, 213 casos multivariados foram detectados $(\mathrm{p}<0,001)$. Destaca-se que as análises foram feitas com e sem casos extremos a fim de auxiliar decisões futuras em relação aos resultados observados. Os casos omissos foram excluídos caso a caso (método pairwise). 
Antes de dar início à análise fatorial, verificou-se a normalidade das variáveis métricas, utilizando o teste de Kolmogorov-Smirnov, pois Field (2009) recomenda que as variáveis tenham distribuição aproximadamente normal antes de serem submetidas à análise fatorial exploratória. Como o teste de Kolmogorov-Smirnov indicou que nenhuma das variáveis métricas possui distribuição normal, esses dados foram padronizados. Então, tanto os dados padronizados quanto os brutos, sem distribuição normal, foram submetidos à análise fatorial exploratória e os resultados foram comparados. Optou-se por utilizar os dados brutos, não padronizados, uma vez que não houve diferença significativa entre os resultados.

\subsubsection{Análise fatorial e validações estatísticas}

Para Tabachnick e Fidell (2007), a análise fatorial é um recurso a ser aplicado a uma série de variáveis quando o pesquisador tem interesse em constatar quais delas formam subconjuntos coesos e relativamente independentes uns dos outros. Segundo Hair, Black, Babin, Anderson e Tatham (2006), entre os propósitos da análise fatorial exploratória está a análise da estrutura das medições. Nessa situação, supõe-se que todas as variáveis das escalas podem ser agrupadas em fatores que garantam a unicidade das medidas. De acordo com Pasquali (2010), a análise fatorial se faz necessária para definir o grau de dimensionalidade do instrumento. Tal análise determina a quantidade de fatores medidos pelo instrumento.

O presente estudo adotou alguns dos critérios definidos por Pasquali (2010) para fins de auxiliar na decisão do número de fatores a serem extraídos de um instrumento: eigenvalues superiores a 1; análise de distribuição eigenvalue (scree plot); análise da consistência interna Alfa de Cronbach; cargas fatoriais acima de 0,30 (positiva ou negativa) e a interpretabilidade comparada à teoria existente sobre o fator ou a escala (Pasquali, 2010).

Também foi utilizado o teste de Kaiser-Meyer-Olklin (KMO), com variação entre 0 e 1. Quanto mais perto de 1, tanto melhor. Figueiredo Filho e Silva Júnior (2010) sugerem a seguinte escala para interpretar o valor da estatística KMO: entre 0,90 e 1 excelente; entre 0,80 e 0,89 bom; entre 0,70 e 0,79 mediano; entre 0,60 e 0,69 medíocre; entre 0,50 e 0,59 ruim e entre 0 e 0,49 inadequado. Já Hair, Black, Babin, Anderson, e Tatham (2006) sugerem 0,50 como patamar aceitável.

O próximo Capítulo apresenta os resultados e discussão dos mesmos. 


\section{Resultados e Discussão}

Neste Capítulo serão apresentados os resultados e análises estatísticas obtidas nesta pesquisa.

\subsection{Resultados descritivos da escala de retenção de talentos}

De modo geral, os participantes da pesquisa acreditam que as práticas organizacionais de retenção de talentos parecem estar gerando resultado positivo. As médias estão elevadas. Todavia, destaca-se, também, que os desvios padrões estão elevados na maioria dos itens, sinalizando que pode haver diferenças de percepções entre os colaboradores considerando a realidade de trabalho de cada um deles. Parece haver heterogeneidade nas percepções.

Importante observar que o item 5 que faz referência à influência da marca "Nome da Organização" na decisão de ingressar na empresa apresentou a maior média $(8,43)$. Apenas o item 2 que faz referência à oportunidade de implementar projetos em conjunto com outras áreas apresentou média inferior a 5 .

A Tabela 5, logo a seguir, apresenta a classificação dos itens referente à percepção das práticas de retenção de talentos, classificados em ordem decrescente, levando-se em consideração a média obtida por cada item junto aos participantes da pesquisa. Também são apresentados os desvios-padrões e a variância.

\section{Tabela 5}

Resultados descritivos da escala de retenção de talentos

Item Média $\begin{gathered}\text { Desvio } \\ \text { Padrão }\end{gathered}$ Variancia Mínimo Máximo

\begin{tabular}{|c|c|c|c|c|c|}
\hline $\begin{array}{l}\text { 5. A solidez da marca "Nome da } \\
\text { Organização" foi importante na minha } \\
\text { decisão de ingressar na empresa. }\end{array}$ & 8,43 & 2,096 & 4,393 & 1 & 10 \\
\hline $\begin{array}{l}\text { 12. Eu me orgulho em trabalhar numa } \\
\text { empresa em que a maioria dos executivos } \\
\text { são funcionários de carreira. }\end{array}$ & 8,21 & 2,026 & 4,103 & 1 & 10 \\
\hline $\begin{array}{l}\text { 6. Os programas de benefícios influenciam } \\
\text { na minha vontade de permanecer na } \\
\text { Organização. }\end{array}$ & 8,11 & 1,899 & 3,608 & 1 & 10 \\
\hline $\begin{array}{l}\text { 9. Reconheço que a Organização é uma } \\
\text { boa empresa para se trabalhar. }\end{array}$ & 8,09 & 1,813 & 3,289 & 1 & 10 \\
\hline $\begin{array}{l}\text { 13. Acredito que posso ascender na } \\
\text { carreira trabalhando nesta Organização. }\end{array}$ & 7,79 & 2,205 & 4,862 & 1 & 10 \\
\hline
\end{tabular}




\begin{tabular}{|c|c|c|c|c|c|}
\hline $\begin{array}{l}\text { 14. A oportunidade de trabalhar em outras } \\
\text { áreas desta Organização, estimula minha } \\
\text { busca por aperfeiçoamento profissional. }\end{array}$ & 7,35 & 2,367 & 5,603 & 1 & 10 \\
\hline $\begin{array}{l}\text { 11. Quem acredita na política de retenção } \\
\text { da Organização está mais satisfeito em } \\
\text { relação ao trabalho. }\end{array}$ & 7,26 & 2,091 & 4,371 & 1 & 10 \\
\hline $\begin{array}{l}\text { 1. Considero que os programas de } \\
\text { ascensão oferecidos pela Organização } \\
\text { (Primeira Investidura, Suregs e } \\
\text { Executivos) contribuem para a retenção de } \\
\text { talentos na Empresa. }\end{array}$ & 7,02 & 2,428 & 5,897 & 1 & 10 \\
\hline $\begin{array}{l}\text { 22. Meu superior imediato expõe com } \\
\text { clareza o nível de desempenho esperado } \\
\text { pelos integrantes da equipe. }\end{array}$ & 6,99 & 2,450 & 6,001 & 1 & 10 \\
\hline $\begin{array}{l}\text { 25. Quem acredita na política de retenção } \\
\text { do Banco é mais comprometido em relação } \\
\text { a quem não acredita. }\end{array}$ & 6,97 & 2,591 & 6,712 & 1 & 10 \\
\hline $\begin{array}{l}\text { 21. Os feedbacks recebidos pelas diversas } \\
\text { fontes (pares, subordinados, superiores) } \\
\text { impactam no aprimoramento do meu } \\
\text { desempenho. }\end{array}$ & 6,72 & 2,447 & 5,989 & 1 & 10 \\
\hline $\begin{array}{l}\text { 15. Eu me sinto motivado ao ver que o } \\
\text { Banco valoriza os talentos presentes no } \\
\text { corpo funcional. }\end{array}$ & 6,67 & 2,477 & 6,136 & 1 & 10 \\
\hline $\begin{array}{l}\text { 3. As ferramentas colaborativas } \\
\text { disponibilizadas pelo Banco (Pensa e } \\
\text { Construção) possibilitam a descoberta de } \\
\text { novos talentos. }\end{array}$ & 6,50 & 2,379 & 5,658 & 1 & 10 \\
\hline $\begin{array}{l}\text { 17. O resultado do meu trabalho é } \\
\text { reconhecimento na minha avaliação de } \\
\text { desempenho. }\end{array}$ & 6,37 & 2,427 & 5,893 & 1 & 10 \\
\hline $\begin{array}{l}\text { 20. No meu ambiente de trabalho, possuo } \\
\text { autonomia para discutir temas relevantes } \\
\text { para o Banco. }\end{array}$ & 6,25 & 2,570 & 6,605 & 1 & 10 \\
\hline $\begin{array}{l}\text { 8. O Banco oferece oportunidades para o } \\
\text { aproveitamento de talentos. }\end{array}$ & 6,23 & 2,382 & 5,674 & 1 & 10 \\
\hline $\begin{array}{l}\text { 19. A liderança exercida pelos meus } \\
\text { superiores contribui de forma positiva, } \\
\text { para o desempenho da equipe. }\end{array}$ & 6,22 & 2,516 & 6,330 & 1 & 10 \\
\hline $\begin{array}{l}\text { 18. As práticas de retenção desenvolvidas } \\
\text { pela Organização impulsionam o meu } \\
\text { desempenho. }\end{array}$ & 6,01 & 2,430 & 5,905 & 1 & 10 \\
\hline $\begin{array}{l}\text { 10. As políticas de retenção de talentos são } \\
\text { uma realidade nesta Organização. }\end{array}$ & 5,92 & 2,355 & 5,547 & 1 & 10 \\
\hline $\begin{array}{l}\text { 24. A política de retenção da Organização } \\
\text { faz com que os funcionários queiram } \\
\text { permanecer nesta organização. }\end{array}$ & 5,82 & 2,434 & 5,923 & 1 & 10 \\
\hline
\end{tabular}


Conclusão

\begin{tabular}{|c|c|c|c|c|c|}
\hline $\begin{array}{l}\text { 7. O estilo de liderança praticado na } \\
\text { Organização valoriza os talentos do corpo } \\
\text { funcional. }\end{array}$ & 5,76 & 2,454 & 6,023 & 1 & 10 \\
\hline $\begin{array}{l}\text { 23. A política de retenção da Organização } \\
\text { funciona. }\end{array}$ & 5,65 & 2,471 & 6,106 & 1 & 10 \\
\hline $\begin{array}{l}\text { 16. As recompensas pelo atingimento de } \\
\text { resultados são proporcionais à minha } \\
\text { dedicação ao trabalho. }\end{array}$ & 5,61 & 2,587 & 6,695 & 1 & 10 \\
\hline $\begin{array}{l}\text { 4. Meu ambiente de trabalho estimula o } \\
\text { desenvolvimento de talentos. }\end{array}$ & 5,38 & 2,433 & 5,920 & 1 & 10 \\
\hline $\begin{array}{l}\text { 2. Em minhas atividades, tenho } \\
\text { oportunidade de implementar projetos em } \\
\text { conjunto com outras áreas da Organização. }\end{array}$ & 4,86 & 2,617 & 6,849 & 1 & 10 \\
\hline
\end{tabular}

\subsection{Resultados descritivos da escala de autoavaliação de desempenho}

Quanto à percepção sobre o próprio desempenho manifestado na Organização, as médias encontram-se elevadas e os desvios padrões estão mais homogêneos (em relação à medida de efetividade das práticas de retenção de talentos). Parece haver maior compartilhamento sobre o desempenho competente manifestado no exercício das atribuições e responsabilidades.

Importante observar que o item 1 "Faço minhas tarefas procurando manter compromisso com esta Organização" apresentou a maior média $(9,35)$. Nenhum dos itens apresentou média inferior a 7 pontos. Ressalta-se, contudo, que pode ter acontecido, aqui, a possível influência de vieses de autorelato, especialmente leniência, o que pode ter inflacionado as percepções dos respondentes.

A Tabela 6, a seguir, apresenta a classificação dos itens referente à medida de autoavaliação de desempenho, classificados em ordem decrescente, também levando-se em consideração a média obtida por cada item junto aos participantes da pesquisa. São apresentados os desvios-padrões e as variâncias. 
Tabela 6

Resultados descritivos da escala de autoavaliação de desempenho

Item Média $\begin{gathered}\text { Desvio } \\ \text { Padrão }\end{gathered}$ Variancia Mínimo Máximo

Padrão

\begin{tabular}{llllll}
\hline 1. Faço minhas tarefas procurando manter & 9,35 &, 938 &, 880 & 3 & 10
\end{tabular}
compromisso com esta Organização.

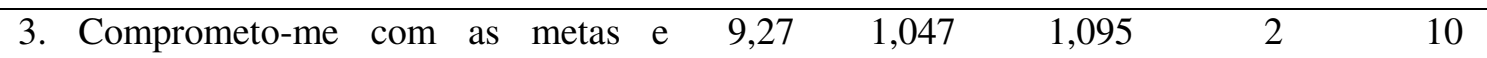
objetivos estabelecidos pela Organização.

\begin{tabular}{llllll}
\hline 21. Desenvolvo o meu trabalho de acordo & 9,19 &, 942 & ,888 & 3 & 10
\end{tabular} com os padrões e normas estabelecidos.

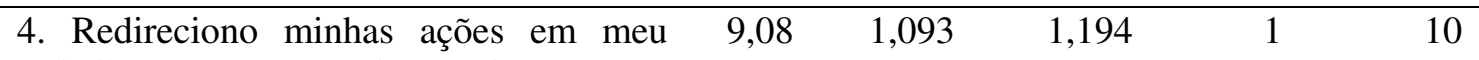
trabalho em razão de mudanças nos objetivos desta Organização.

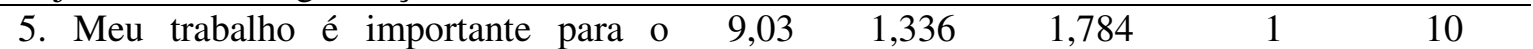
desempenho desta Organização.

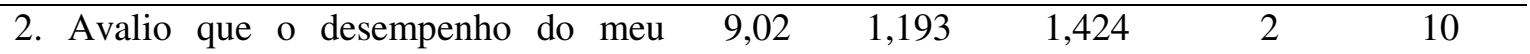
trabalho contribui diretamente para a consecução da missão e objetivos desta Organização.

\begin{tabular}{|c|}
\hline 9. Implement \\
\hline
\end{tabular}
quando detecto algum erro ou falha em meu trabalho.

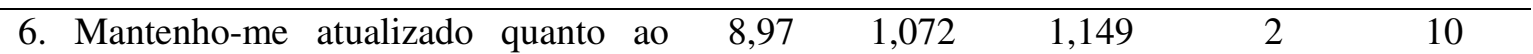
conhecimento técnico em minha área de atuação.

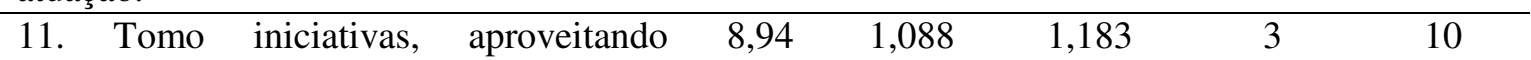
oportunidades que possam gerar a melhoria dos resultados.

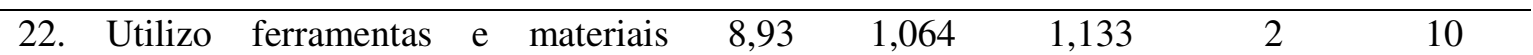
disponíveis para a melhoria dos resultados de meu trabalho.

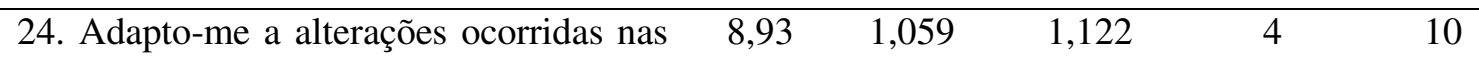
minhas rotinas de trabalho.

\begin{tabular}{llllll}
\hline 8. Direciono minhas ações para realizar o & 8,86 & 1,100 & 1,210 & 2 & 10
\end{tabular} meu trabalho com economia de recursos.

\begin{tabular}{lllllll}
\hline $\begin{array}{l}\text { 25. Estabeleço prioridades em meu } \\
\text { trabalho, definindo ações, prazos e } \\
\text { recursos necessários. }\end{array}$ & & & 1,231 & 1,514 & 1 & 10 \\
\hline $\begin{array}{l}\text { 27. Avalio que a busca pela melhoria de } \\
\text { meu desempenho me motiva a tentar fazer }\end{array}$ & & & & & \\
um trabalho melhor. & & & & & 1,324 \\
$\begin{array}{l}\text { 23. Planejo ações de acordo com minhas } \\
\text { tarefas e rotinas organizacionais. }\end{array}$ & 8,74 & 1,235 & 1,526 & 1 & 10 \\
\end{tabular}


Conclusão

\begin{tabular}{|c|c|c|c|c|c|}
\hline $\begin{array}{l}\text { 10. Eu sei o que é esperado de mim em } \\
\text { termos de meu desempenho no trabalho. }\end{array}$ & 8,73 & 1,532 & 2,347 & 1 & 10 \\
\hline $\begin{array}{l}\text { 15. Direciono minhas ações a partir do } \\
\text { conhecimento da estrutura e das políticas } \\
\text { da empresa. }\end{array}$ & 8,65 & 1,286 & 1,654 & 3 & 10 \\
\hline $\begin{array}{l}\text { 7. Mantenho um canal permanente de } \\
\text { comunicação, favorecendo a interação } \\
\text { com outras pessoas. }\end{array}$ & 8,63 & 1,401 & 1,963 & 1 & 10 \\
\hline $\begin{array}{l}\text { 12. Meu desempenho no trabalho está de } \\
\text { acordo com aquilo que é esperado de mim. }\end{array}$ & 8,62 & 1,303 & 1,699 & 1 & 10 \\
\hline $\begin{array}{l}\text { 26. Estabeleço a relação entre a origem e a } \\
\text { finalidade do meu trabalho. }\end{array}$ & 8,62 & 1,393 & 1,940 & 1 & 10 \\
\hline $\begin{array}{l}\text { 20. Avalio satisfatoriamente o meu } \\
\text { desempenho na consecução de tarefas e } \\
\text { rotinas relacionadas ao meu trabalho. }\end{array}$ & 8,57 & 1,240 & 1,538 & 1 & 10 \\
\hline $\begin{array}{l}\text { 13. As tarefas que me são destinadas } \\
\text { exigem que eu me esforce muito para } \\
\text { realizá-las. }\end{array}$ & 8,42 & 1,726 & 2,979 & 1 & 10 \\
\hline $\begin{array}{l}\text { 17. Estabeleço intercâmbio com outras } \\
\text { equipes ou unidades, quando necessário, } \\
\text { para garantir o atingimento dos objetivos } \\
\text { organizacionais. }\end{array}$ & 7,99 & 1,961 & 3,846 & 1 & 10 \\
\hline $\begin{array}{l}\text { 16. Contribuo com alternativas para } \\
\text { solução de problemas e melhoria de } \\
\text { processos desta Organização. }\end{array}$ & 7,99 & 1,726 & 2,980 & 1 & 10 \\
\hline $\begin{array}{l}\text { 19. Percebo o impacto de minhas ações e } \\
\text { do resultado do meu trabalho sobre as } \\
\text { outras áreas desta Organização. }\end{array}$ & 7,55 & 2,217 & 4,914 & 1 & 10 \\
\hline $\begin{array}{l}\text { 14. Recebo orientações adequadas à } \\
\text { realização das tarefas sob minha } \\
\text { responsabilidade. }\end{array}$ & 7,38 & 2,010 & 4,040 & 1 & 10 \\
\hline $\begin{array}{l}\text { 18. São realizados encontros e reuniões } \\
\text { grupos entre mim e meus colegas/pares e } \\
\text { chefia para discussão e avaliação das ações } \\
\text { e tarefas realizadas. }\end{array}$ & 7,35 & 2,400 & 5,761 & 1 & 10 \\
\hline
\end{tabular}

\subsection{Resultados descritivos da escala de satisfação no trabalho}

Os dados (secundários) concernentes à satisfação com o trabalho assemelham-se aos dados obtidos na medida de retenção de talentos (médias e desviões padrões mais elevados). O item 5 "Compartilho dos valores disseminados pela minha empresa" apresentou a maior média $(8,71)$. Apenas o item 16 , que faz referência à meritocracia nos processos de ascensão, obteve média inferior a 6 .

A Tabela 7 sintetiza os escores dos itens referentes à escala de satisfação no trabalho. 
Tabela 7

Resultados descritivos da escala de satisfação no trabalho

Item Média $\begin{gathered}\text { Desvio } \\ \text { Padrão }\end{gathered}$ Variança Mínimo Máximo

\begin{tabular}{llllll}
\hline $\begin{array}{l}\text { 5. Compartilho dos valores disseminados } \\
\text { pela minha empresa. }\end{array}$ & 8,71 & 1,477 & 2,181 & 1 & 10
\end{tabular}

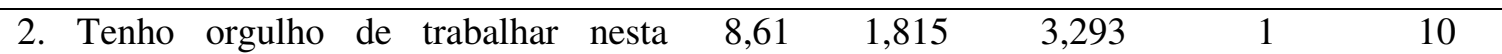
Empresa.

\begin{tabular}{llllll}
\hline 10. Meu trabalho tem significado pessoal & 8,30 & 2,021 & 4,083 & 1 & 10
\end{tabular} para mim.

\begin{tabular}{llllll}
\hline $\begin{array}{l}\text { 3. Considero relevantes as contribuições } \\
\text { que o meu trabalho traz para a sociedade. }\end{array}$ & 8,25 & 1,833 & 3,362 & 1 & 10 \\
& & & & & \\
\hline 11. Sinto-me parte desta empresa. & 8,24 & 2,121 & 4,500 & 1 & 10
\end{tabular}

\begin{tabular}{l}
$\begin{array}{l}\text { 9. Ponho em prática minhas habilidades e } \\
\text { capacidades no trabalho. }\end{array}$ \\
\hline
\end{tabular}

\begin{tabular}{|c|c|c|c|c|c|}
\hline $\begin{array}{l}\text { 4. Executo tarefas diversificadas em meu } \\
\text { trabalho. }\end{array}$ & 7,92 & 2,147 & 4,608 & 1 & 10 \\
\hline
\end{tabular}

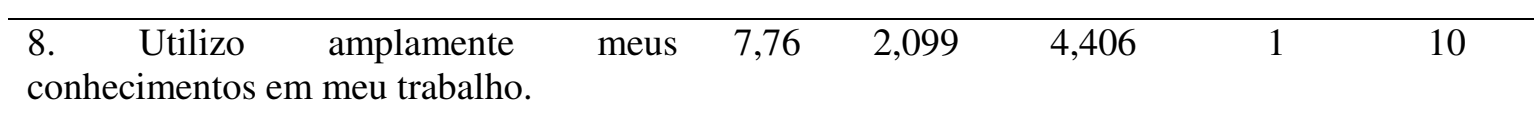

\begin{tabular}{llllll}
\hline 6. O meu trabalho é fonte de inspiração & 7,75 & 2,167 & 4,695 & 1 & 10
\end{tabular} para mim.

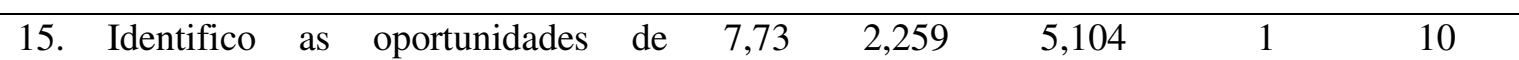
ascensão profissional existentes na Empresa.

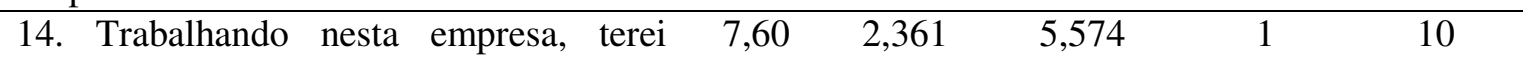
oportunidade de fazer carreira e crescer.

\begin{tabular}{llllll}
\hline 1. Estou satisfeito (a) com meu trabalho. & 7,50 & 2,074 & 4,300 & 1 & 10
\end{tabular}

\begin{tabular}{llllll}
\hline $\begin{array}{l}\text { 7. Sinto-me motivado e entusiasmado com } \\
\text { o trabalho que realizo. }\end{array}$ & 7,46 & 2,281 & 5,204 & 1 & 10 \\
\hline $\begin{array}{l}\text { 12. Recebo um salário compatível com a } \\
\text { responsabilidade que me é conferida. }\end{array}$ & 6,30 & 2,587 & 6,693 & 1 & 10 \\
\hline $\begin{array}{l}\text { 13. O meu salário é compatível com os } \\
\text { valores pagos para a minha função no } \\
\text { mercado financeiro. }\end{array}$ & & & & & \\
\hline $\begin{array}{l}\text { 16. A ascensão na Organização acontece } \\
\text { por mérito e competência. }\end{array}$
\end{tabular}

Fonte: Dados da pesquisa. 
Como requisito para o atingimento do objetivo geral e alguns dos objetivos específicos desta pesquisa, foram realizadas validações fatoriais exploratórias dos instrumentos utilizados. A próxima Seção descreve os resultados das análises fatoriais e de consistência interna das escalas de retenção de talentos, autoavaliação de desempenho e satisfação no trabalho.

\subsection{Escala de Retenção de Talentos}

Para a validação estatística da Escala de Retenção de Talentos, foram inicialmente adotados os procedimentos para avaliar o grau de fatorabilidade da escala. Para isso foram calculadas a medida Kayser-Meyer-Olklin (KMO), a variância total explicada, as cargas fatoriais e a consistência interna.

A matriz de correlações se mostrou fatorável, com $\mathrm{KMO}=0,971$, demonstrando um índice excelente de fatorabilidade dos dados (Field, 2009; Hair et al., 2006). Em relação à quantidade de fatores, foi possível extrair três fatores, tanto por meio da análise do diagrama de declividade, ou Scree Plot (Figura 2), quanto por meio do critério de Eigenvalues superior a 1.

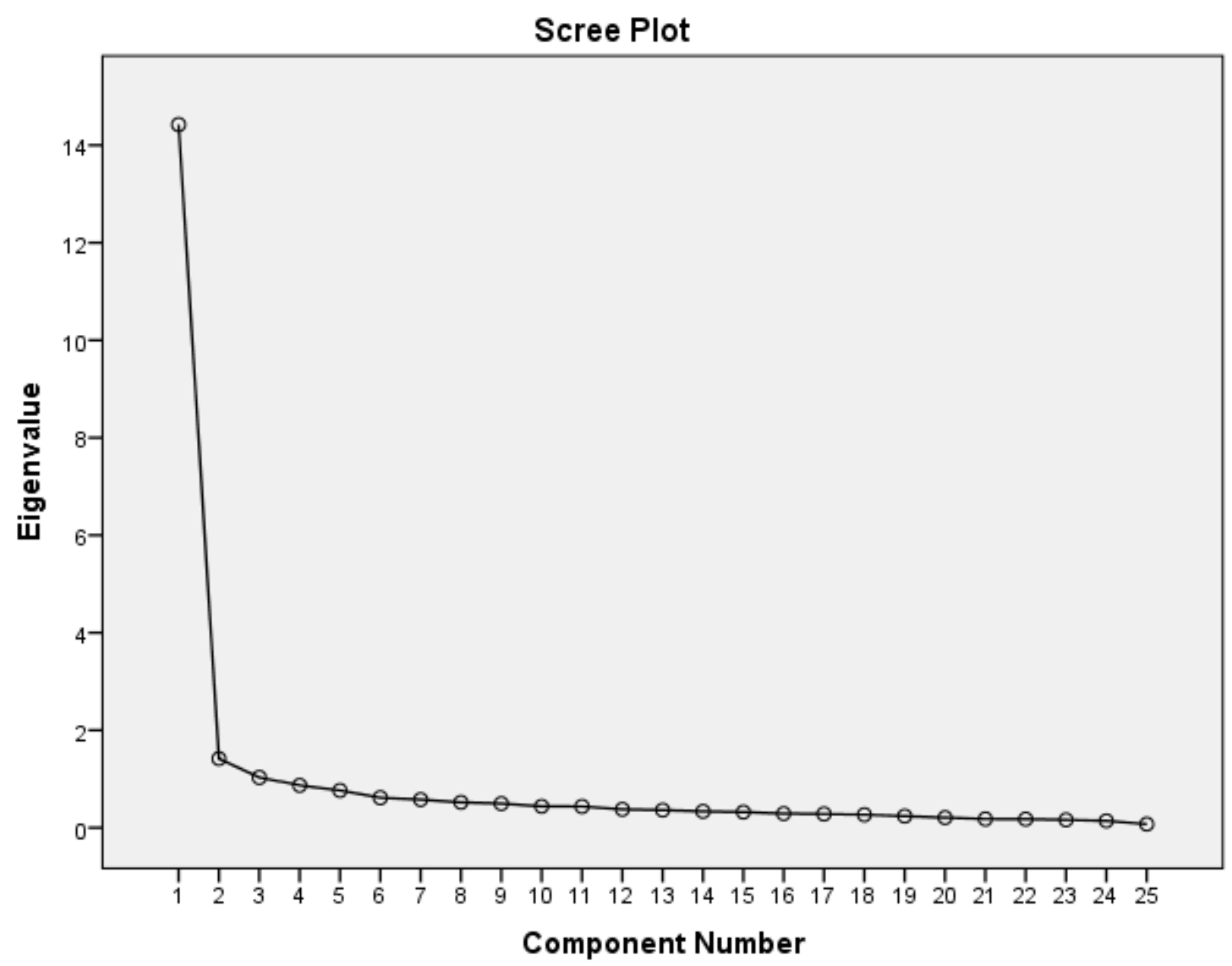

Figura 2. Scree Plot - Retenção de Talentos

Fonte: Dados da pesquisa 
Esses três fatores explicaram, conjuntamente, 67,48 \% da variância total dos itens. Ressalta-se que os agrupamentos apresentaram lógica conceitual e alinhamento com as teorias utilizadas por esta pesquisa. As cargas fatoriais foram bastante satisfatórias, oscilando entre 0,533 e 0,920. Nenhuma das variáveis apresentou cargas compartilhadas. Os Alphas de Cronbach dos fatores também foram aceitáveis, variando de 0,806 a 0,961. Os resultados da análise fatorial encontram-se sintetizados na Tabela 8 .

\section{Tabela 8}

Estrutura fatorial da Escala de Retenção de Talentos

\begin{tabular}{|c|c|c|c|c|c|}
\hline Fator & $\begin{array}{l}\text { Variancia } \\
\text { Explicada } \\
\end{array}$ & Itens & $\begin{array}{c}\text { Carga } \\
\text { Fatorial } \\
\end{array}$ & Comunalidades & $\begin{array}{l}\text { Alpha de } \\
\text { Cronbach }\end{array}$ \\
\hline \multirow{16}{*}{$\begin{array}{l}\text { Gestão de } \\
\text { Talentos }\end{array}$} & \multirow{16}{*}{$57,695 \%$} & R10 & 0,920 & 0,801 & \multirow{16}{*}{0,961} \\
\hline & & R23 & 0,913 & 0,819 & \\
\hline & & $\mathrm{R} 24$ & 0,902 & 0,554 & \\
\hline & & $\mathrm{R} 8$ & 0,815 & 0,768 & \\
\hline & & R25 & 0,784 & 0,815 & \\
\hline & & $\mathrm{R} 18$ & 0,780 & 0,583 & \\
\hline & & $\mathrm{R} 1$ & 0,779 & 0,790 & \\
\hline & & $\mathrm{R} 11$ & 0,720 & 0,718 & \\
\hline & & $\mathrm{R} 15$ & 0,715 & 0,533 & \\
\hline & & $\mathrm{R} 3$ & 0,668 & 0,604 & \\
\hline & & $\mathrm{R} 16$ & 0,632 & 0,554 & \\
\hline & & R7 & 0,630 & 0,436 & \\
\hline & & $\mathrm{R} 2$ & 0,537 & 0,625 & \\
\hline & & R13 & 0,501 & 0,665 & \\
\hline & & $\mathrm{R} 14$ & 0,477 & 0,516 & \\
\hline & & $\mathrm{R} 4$ & 0,381 & 0,670 & \\
\hline \multirow{5}{*}{$\begin{array}{c}\text { Performance } \\
\text { de Talentos }\end{array}$} & \multirow{5}{*}{$5,664 \%$} & R17 & $-0,676$ & 0,713 & \multirow{5}{*}{0,909} \\
\hline & & $\mathrm{R} 21$ & $-0,737$ & 0,670 & \\
\hline & & $\mathrm{R} 20$ & $-0,749$ & 0,716 & \\
\hline & & R19 & $-0,795$ & 0,791 & \\
\hline & & $\mathrm{R} 22$ & $-0,939$ & 0,747 & \\
\hline \multirow{4}{*}{$\begin{array}{l}\text { Atração e } \\
\text { Retençãa }\end{array}$} & \multirow{4}{*}{$4,120 \%$} & R5 & 0,769 & 0,559 & \multirow{4}{*}{0,806} \\
\hline & & R6 & 0,637 & 0,598 & \\
\hline & & R9 & 0,587 & 0,684 & \\
\hline & & R12 & 0,568 & 0,693 & \\
\hline
\end{tabular}

Fonte: Dados da pesquisa

Para denominação dos fatores, retornou-se à literatura para denominar os fatores encontrados. Segundo Almeida (2004), o fator gestão de talentos reflete uma atuação integrada da área de recursos humanos focada em estratégias organizacionais e competências. Além disso, a autora sustenta que a gestão de talentos possui um enfoque estratégico decorrente dos processos de captação, seleção, retenção e desenvolvimento dos talentos individuais e organizacionais. 
Para Lewis e Rechman (2006), o fator performance de talentos diz respeito à atribuição organizacional de gerenciar a performance dos indivíduos talentos, de forma não diferenciada. Ainda segundo os autores, o fator atração e retenção refere-se ao trabalho conjunto da área de recursos humanos e gestão de talentos no intuito de criar condições favoráveis para atrair e reter os profissionais altamente competentes, independente da função exercida.

\subsection{Escala de Autoavaliação de Desempenho}

O KMO obtido para a medida de autoavaliação de desempenho no trabalho correspondeu a 0,970 . Inicialmente a primeira extração apresentou quatro fatores, conforme proposto por (Coelho Jr. et al., 2010), porém o último fator apresentou baixa consistência interna, com Alpha de Cronbach de 0,612.

Dessa forma, forçou-se uma solução com três fatores. Esses fatores apresentaram autovalores (Eigenvalues) maiores do que 1 e a análise do Scree Plot (Figura 3) corrobora esse resultado. Esses três fatores explicaram, conjuntamente, $62,183 \%$ da variância total dos itens. $\mathrm{O}$ agrupamento dos itens teóricos em fatores empíricos confirmou a estrutura conceitual original da escala. As cargas fatoriais variaram entre 0,348 e 0,903. Apenas um item (2.1) foi excluído, por apresentar carga fatorial de 0,24. Nenhum dos itens apresentou cargas compartilhadas entre os fatores. Os Alphas também foram aceitáveis, oscilando entre 0,953 a 0,807. Os resultados detalhados encontram-se na Tabela 9. 


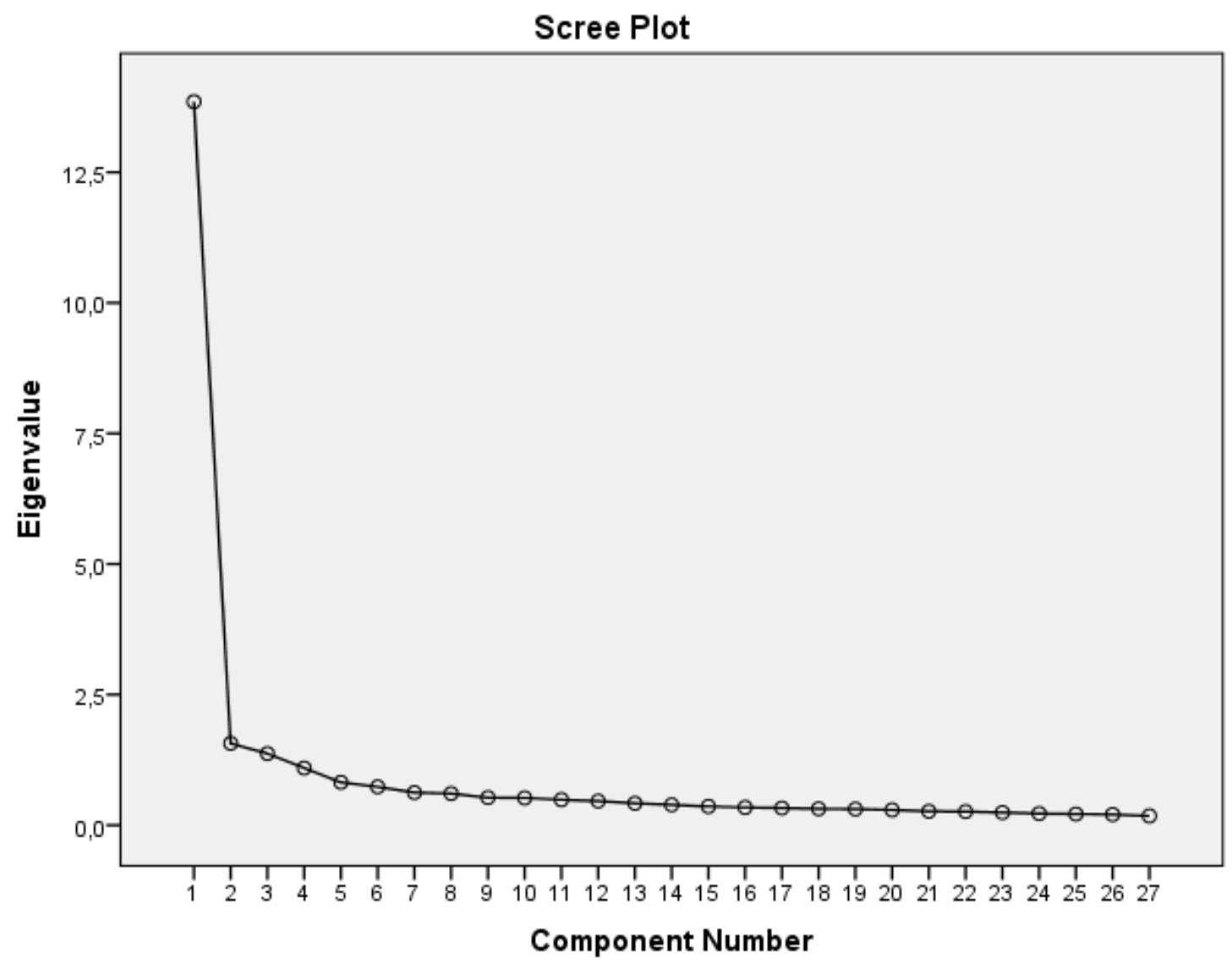

Figura 3. Scree Plot - Autoavaliação de Desempenho

Fonte: Dados da pesquisa

Tabela 9

Estrutura fatorial da Escala de Autoavaliação de Desempenho

\begin{tabular}{cccccc}
\hline Fator & $\begin{array}{c}\text { Variancia } \\
\text { Explicada }\end{array}$ & Itens & $\begin{array}{c}\text { Carga } \\
\text { Fatorial }\end{array}$ & Comunalidades & $\begin{array}{c}\text { Alpha de } \\
\text { Cronbach }\end{array}$ \\
\hline & & A4.6 & 0,903 & 0,689 & \\
& A4.4 & 0,894 & 0,743 & \\
& A4.5 & 0,831 & 0,717 & \\
Autogerenciamento & \multirow{2}{*}{$51,304 \%$} & A4.7 & 0,824 & 0,688 & \\
do Desempenho & & A4.3 & 0,719 & 0,666 & \\
& & A4. 4 & 0,658 & 0,651 & \\
& & A4.1 & 0,649 & 0,693 & 0,953 \\
& A1.12 & 0,484 & 0,569 & \\
& & A1.11 & 0,448 & 0,517 & \\
& & A1.6 & 0,431 & 0,487 & \\
& A1.8 & 0,421 & 0,557 & \\
& A1.9 & 0,418 & 0,59 & \\
& & A1.7 & 0,363 & 0,512 & \\
\hline
\end{tabular}


Conclusão

\begin{tabular}{|c|c|c|c|c|c|}
\hline & \multirow{7}{*}{$5,8 \%$} & A3.3 & 0,739 & 0,459 & \multirow{7}{*}{0,807} \\
\hline Execução, & & A 3.4 & 0,696 & 0,514 & \\
\hline Monitoramento e & & A3.1 & 0,618 & 0,569 & \\
\hline Revisão do & & A 3.2 & 0,604 & 0,47 & \\
\hline \multirow[t]{5}{*}{ Desempenho } & & A 2.2 & 0,508 & 0,323 & \\
\hline & & A 2.3 & 0,330 & 0,552 & \\
\hline & & A 2.1 & 0,237 & 0,118 & \\
\hline & & A1.2 & 0,817 & 0,702 & \multirow{6}{*}{0,902} \\
\hline & & A 1.3 & 0,805 & 0,767 & \\
\hline Regulação de & $5.078 \%$ & A1.4 & 0,742 & 0,723 & \\
\hline \multirow[t]{3}{*}{ Desempenho } & & A1.1 & 0,732 & 0,661 & \\
\hline & & A 1.5 & 0,725 & 0,629 & \\
\hline & & A1.10 & 0,348 & 0,409 & \\
\hline
\end{tabular}

Fonte: Dados da pesquisa

Levando-se em consideração que a escala original era composta por quatro fatores, voltou-se à literatura para denominar os fatores encontrados. Segundo Coelho Jr. et.al (2010), o fator autogerenciamento do desempenho abrange os itens que tratam da eficiência do desempenho, em especial, da capacidade individual de administrar a execução do próprio trabalho.

Para o autor, o fator execução, monitoramento e revisão do desempenho diz respeito das dimensões ou facetas que envolvem o foco no processo de trabalho e desenvolvimento de tarefas e ações contando, inclusive, com o ajustamento dos objetivos e estratégias organizacionais mais sistêmicas.

Ainda segundo o mesmo autor, o fator regulação do desempenho trata da adequação à ação pelo indivíduo, assim como o quanto o mesmo percebe que seu trabalho contribui para o atingimento da missão e estratégia da organização em estudo (centralidade do trabalho).

\subsection{Escala de Satisfação no trabalho}

Para obtenção dos escores fatoriais, foram aplicados os mesmos procedimentos anteriores. $\mathrm{O}$ valor encontrado para o critério KMO foi de 0,933 , mostrando-se empiricamente favorável para a adequação fatorial. Foram extraídos dois fatores que, conjuntamente, explicaram 68,497\% da variancia total. Esses fatores apresentaram autovalores (Eigenvalues) maiores do que 1 e a análise do Scree Plot (Figura 4) corrobora esse resultado. 


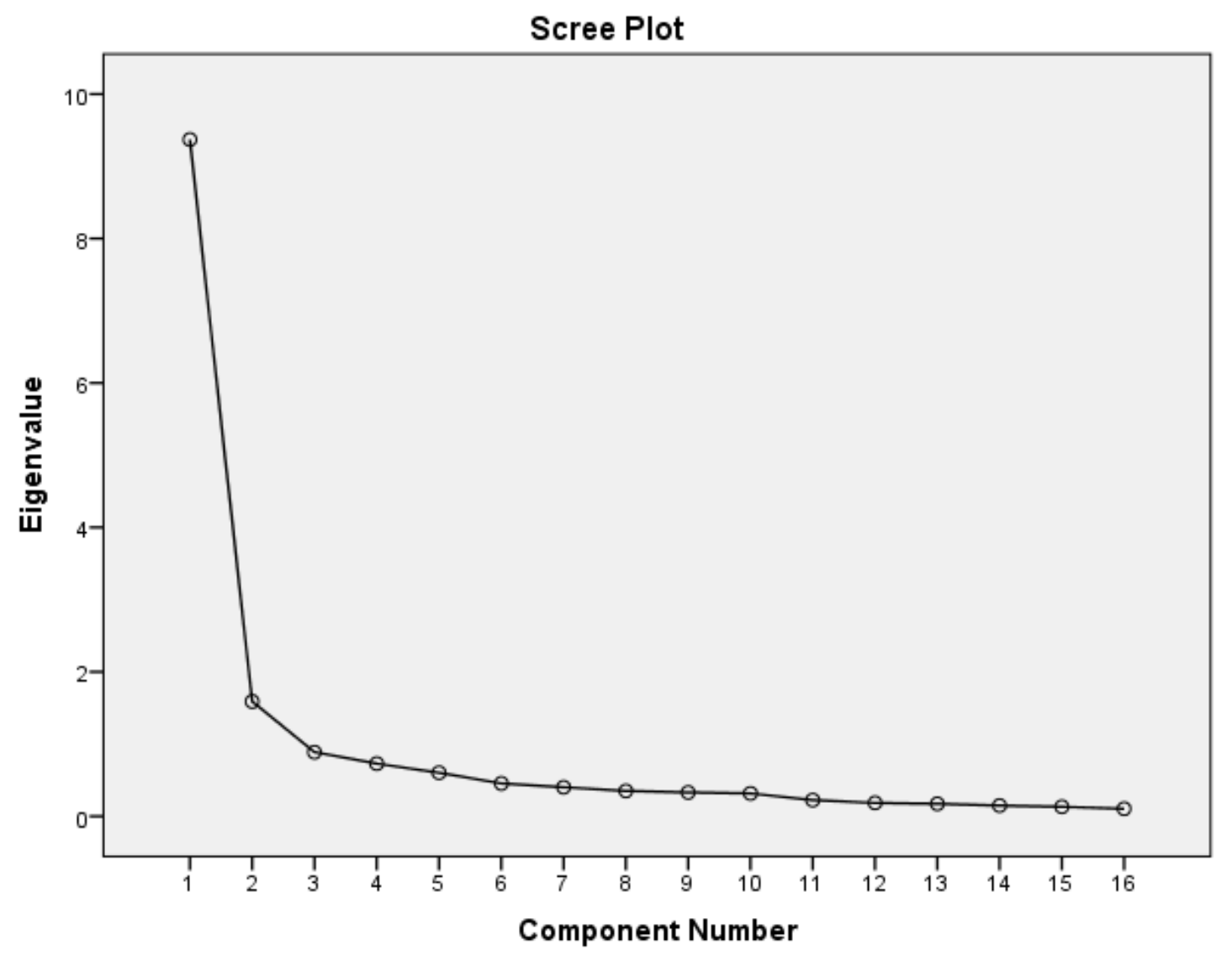

Figura 4. Scree Plot - Satisfação com o trabalho Fonte: Dados da pesquisa

As cargas fatoriais variaram entre 0,611 e 0,903. Nenhum dos itens apresentou cargas compartilhadas entre os fatores empíricos, e os Alphas também foram aceitáveis. $\mathrm{O}$ detalhamento dos resultados pode ser verificado na Tabela 10.

Tabela 10

Estrutura fatorial da Escala de Satisfação no trabalho

\begin{tabular}{|c|c|c|c|c|c|}
\hline Fator & $\begin{array}{l}\text { Variancia } \\
\text { Explicada }\end{array}$ & Itens & $\begin{array}{c}\text { Carga } \\
\text { Fatorial }\end{array}$ & Comunalidades & $\begin{array}{l}\text { Alpha de } \\
\text { Cronbach }\end{array}$ \\
\hline \multirow{11}{*}{$\begin{array}{c}\text { Engajamento } \\
\text { com o } \\
\text { trabalho }\end{array}$} & & S3 & 0,876 & 0,658 & \\
\hline & & S6 & 0,868 & 0,802 & \\
\hline & & S9 & 0,865 & 0,679 & \\
\hline & & S8 & 0,851 & 0,654 & \\
\hline & $58,543 \%$ & S10 & 0,848 & 0,736 & 0.948 \\
\hline & & S7 & 0,816 & 0,815 & \\
\hline & & S5 & 0,780 & 0,615 & \\
\hline & & S11 & 0,695 & 0,702 & \\
\hline & & S4 & 0,691 & 0,453 & \\
\hline & & S2 & 0,657 & 0,659 & \\
\hline & & S1 & 0,626 & 0,685 & \\
\hline
\end{tabular}


Conclusão

\begin{tabular}{cccccc}
\hline Salários e & & S13 & 0,903 & 0,720 & \\
oportunidades & $9,934 \%$ & S12 & 0,886 & 0,724 & \multirow{2}{*}{0,882} \\
de & S16 & 0,725 & 0,655 & \\
crescimento & & S14 & 0,627 & 0,733 & \\
\hline Fonte: Dados da pesquisa & S15 & 0,611 & 0,669 & \\
\hline
\end{tabular}

Para confirmação da denominação dos fatores, retornou-se à literatura para denominar os fatores encontrados. De acordo com Martinsa et al. (2016), o fator engajamento com o trabalho traduz o comportamento no qual as pessoas trazem ou deixam seus Eus, durante o desempenho das tarefas. Já para Simpson (2009), o engajamento pessoal é posteriormente descrito como o emprego ou expressão de uma pessoa no trabalho, seja fisicamente, emocionalmente ou cognitivamente.

Para Valle (2009), o fator salário e oportunidades de crescimento, trata do recebimento de remuneração direta e indireta baseadas em políticas organizacionais e decorrente do desempenho e produtividade do trabalhador, além da oportunidade de aprender e progredir dentro da organização.

Após serem apresentadas as estruturas fatoriais das escalas, a próxima Seção tratará da testagem empírica do modelo de regressão teórico hipotetizado.

\subsection{Modelos Empíricos}

Para facilitar a interpretação dos resultados, as variáveis categóricas foram transformadas em dummies. As correlações entre as variáveis antecedentes (escores fatoriais de satisfação com o trabalho, escores fatoriais da percepção de efetividade das práticas de retenção de talentos, dados pessoais e dados profissionais) foram bastante significativas. Os dados encontram-se apresentados na Tabela 11. 
Tabela 11

Matriz de correlação entre as variáveis

\begin{tabular}{|c|c|c|c|c|c|c|c|c|c|c|c|c|c|c|c|c|c|c|c|c|c|}
\hline & 1 & 2 & 3 & 4 & 5 & 6 & 7 & 8 & 9 & 10 & 11 & 12 & 13 & 14 & 15 & 16 & 17 & 18 & 19 & 20 & 21 \\
\hline 1 & 1 &,- 026 &,- 031 &,- 019 & 032 & ,018 &, $063^{*}$ &,$- 183^{* *}$ &,- 035 &, 053 &, $178^{* *}$ &, $072^{*}$ & ,628** &,$- 065^{*}$ &,- 036 &,- 001 & ,029 &, $073^{*}$ & ,012 &, 062 &,- 045 \\
\hline 2 & & 1 & ,632** &,- 011 &,- 007 &,- 001 &,- 006 &,- 017 &,- 004 & ,040 &,- 006 &,- 003 &,- 024 &,- 008 &,- 010 &,- 023 &,- 023 &,- 032 &,- 013 &.$^{\mathrm{c}}$ &.$^{\mathrm{c}}$ \\
\hline 3 & & & 1 &,- 018 &,- 012 &,- 002 &,- 010 &, 013 &,- 007 &, 045 &,- 010 &,- 005 &,- 023 &, 010 & ,008 & 011 &,- 042 &,- 061 &,- 024 &,- 025 &,- 053 \\
\hline 4 & & & & 1 &,- 044 &,- 008 &, $065^{*}$ &,$- 079^{* *}$ &,- 026 &, $065^{*}$ &,- 008 &,- 018 &,- 016 &, 027 &,- 008 &,- 002 &, 004 &,- 043 &,- 014 & ,042 & 001 \\
\hline 5 & & & & & 1 &,- 005 & $087^{* * *}$ &, 046 & 038 &,- 015 & 016 &,- 012 &, 009 &,- 038 &,- 023 &,- 051 & ,007 &,- 039 &,- 019 &,- 059 &,- 024 \\
\hline 6 & & & & & & 1 &,- 005 &,- 012 &,- 003 &, $070^{*}$ &,- 004 &,- 002 &,- 005 & 040 & 018 &, 036 & ,013 & 035 & 035 &, 030 &, 054 \\
\hline 7 & & & & & & & 1 &,- 059 &,- 015 &,$- 066^{*}$ &,- 021 &,- 010 &, 036 &,- 013 & ,001 &,- 025 &,- 052 &,- 036 &,- 059 &,$- 089^{* * *}$ &,- 042 \\
\hline 8 & & & & & & & & 1 &,- 040 &,$- 172^{* * *}$ &,- 056 &,- 027 &,- 059 & 056 & ,032 & 037 & 061 & 007 &,- 001 &, 006 & 041 \\
\hline 9 & & & & & & & & & 1 &,- 044 &,- 014 &,- 007 &,- 022 & ,042 &, 057 & ,004 &, 005 &,- 001 &,- 025 & ,000 & 040 \\
\hline 10 & & & & & & & & & & 1 &,$- 062^{*}$ &,- 030 &, $065^{*}$ & $180^{\text {*** }}$ & $124^{* * *}$ & $148^{* * *}$ &,- 014 &, 047 & $089^{* * *}$ & $139^{* * *}$ & $199^{* *}$ \\
\hline 11 & & & & & & & & & & & 1 &,- 010 & $287^{* *}$ &, $129^{* * *}$ & $120^{* * *}$ &, $089^{\text {** }}$ &, $090^{* * *}$ & $116^{* *}$ &, $114^{* *}$ &, $126^{\text {** }}$ & $113^{* *}$ \\
\hline 12 & & & & & & & & & & & & 1 & $115^{* *}$ &, 052 &, $066^{*}$ &, 021 & ,029 &, 053 &, 025 &, 042 & ,039 \\
\hline 13 & & & & & & & & & & & & & 1 & 040 &, $064^{*}$ &, 053 &, 039 &, $082^{*}$ & ,017 &, $088^{* * *}$ & 020 \\
\hline 14 & & & & & & & & & & & & & & 1 &, $792^{* * *}$ & $736^{* *}$ & $339^{* *}$ &, $506^{* * *}$ &, $414^{* * *}$ &, $639^{* *}$ &, $788^{* *}$ \\
\hline 15 & & & & & & & & & & & & & & & 1 &, $592^{* * *}$ &, $364^{* * *}$ &, $584^{* *}$ &, $431^{* *}$ &, $576^{* * *}$ & $650^{* * *}$ \\
\hline 16 & & & & & & & & & & & & & & & & 1 &, $456^{* * *}$ &, $459^{\text {** }}$ &, $520^{* *}$ &, $713^{* * *}$ & $653^{* *}$ \\
\hline 17 & & & & & & & & & & & & & & & & & 1 & $672^{* *}$ & $801^{* *}$ &, $598^{* * *}$ & $339^{* *}$ \\
\hline 18 & & & & & & & & & & & & & & & & & & 1 &, $640^{* * *}$ &, $606^{* *}$ & $468^{* *}$ \\
\hline 19 & & & & & & & & & & & & & & & & & & & 1 &, $639^{\text {** }}$ &, $382^{* *}$ \\
\hline 20 & & & & & & & & & & & & & & & & & & & & 1 & $672^{* *}$ \\
\hline 21 & & & & & & & & & & & & & & & & & & & & & 1 \\
\hline
\end{tabular}

Nota. (1) Idade (2) Ensino Médio (3) Superior em Andamento (4) Superior (5) Mestrado (6) Doutorado (7) Técnicos (8) Assessores (9) Auditores (10) Primeiros Gestores (11)

Superintendentes (12) Executivos (13) Tempo de Banco (14) Gestão de Talentos (15) Desempenho (16) Atração e Retenção (17) Autogerenciamento do Desempenho (18)

Execução, Monitoramento e Revisão do Desempenho (19) Regulação do Desempenho (20) Engajamento com o Trabalho (21) Salários e Oportunidades de Crescimento 
Como se pode notar na matriz de correlação, os fatores relacionados à autoavaliação de desempenho (regulação do desempenho; autogerenciamento do desempenho) apresentaram correlação forte entre si $(r \geq 0,7)$. Da mesma forma, os fatores ligados à retenção (desempenho; atração e retenção; gestão de talentos) também apresentaram correlação forte entre si, além de se correlacionarem fortemente com os fatores que dizem respeito à satisfação (engajamento com o trabalho; salários e oportunidades de crescimento).

Apresentaram correlação moderada $(r \geq 0,4)$ os fatores ligados a autoavaliação de desempenho (autogerenciamento do desempenho; execução, monitoramento e revisão do desempenho, regulação do desempenho) e os fatores ligados à retenção (gestão de talentos; desempenho; atração e retenção). Seguindo o mesmo padrão, os fatores pessoais (ensino médio, superior) se correlacionaram moderadamente entre si, assim como com os fatores pessoais (idade) e profissionais (tempo de banco).

Quanto à testagem dos modelos empíricos, nos resultados obtidos a partir dos procedimentos adotados de regressão múltipla stepwise, é possível identificar a predição de cada uma das variáveis antecedentes que contribuíram de forma estatisticamente significativa com tamanhos de efeito diversificados em relação às variáveis critério dos modelos testados. Ressalta-se, aqui, que foram calculados os escores fatoriais para cada um dos fatores empíricos encontrados nas três Escalas utilizadas. É importante ressaltar ainda que foram testados três modelos, a partir de cada fator verificado na escala de autoavaliação de desempenho. Cada um destes fatores foi testado como variável critério. As mesmas variáveis antecedentes foram testadas em todos os três modelos obtidos.

Nota-se que em todos os modelos empíricos testados, a percepção de efetividade das práticas de retenção de talentos foi preditora de desempenho. Quanto mais positiva a percepção de efetividade destas práticas, mais favoravelmente o desempenho era percebido

\subsubsection{Variável Critério: Autogerenciamento de Desempenho}

A Tabela 12 apresenta os indicadores estatísticos obtidos para a variável critério “Autogerenciamento de Desempenho" (coeficientes de regressão padronizados (beta), o R² ajustado, o R ${ }^{2}$ e o R para cada regressão feita. 
Tabela 12

Resultados Regressão Linear - Variável Critério: Autogerenciamento do Desempenho

\begin{tabular}{lccccc}
\hline \multirow{2}{*}{ Variáveis Explicativas } & \multicolumn{4}{c}{ Modelos empíricos reduzidos (Valor de $\boldsymbol{\beta}$ ) } \\
\cline { 2 - 6 } & I & II & III & IV & V \\
\hline Engajamento com o trabalho & 0,600 & 0,614 & 0,676 & 0,616 & 0,620 \\
\hline Primeiros gestores & & $-0,099$ & $-0,088$ & $-0,088$ & $-0,880$ \\
\hline Salários e oportunidades de crescimento & & & $-0,94$ & $-0,132$ & $-0,134$ \\
\hline Atração e retenção & & & & 0,119 & 0,120 \\
\hline Mestrado & & & & & 0,057 \\
\hline $\mathbf{R}^{2}$ & 0,360 & 0,370 & 0,375 & 0,381 & 0,384 \\
\hline $\mathbf{R}^{2}$ Ajustado & 0,359 & 0,368 & 0,372 & 0,378 & 0,380 \\
\hline $\mathbf{R}$ & $0,600^{\mathrm{a}}$ & $0,608^{\mathrm{b}}$ & $0,612^{\mathrm{c}}$ & $0,617^{\mathrm{d}}$ & $0,620^{\mathrm{e}}$ \\
\hline
\end{tabular}

Fonte: Dados da pesquisa

$* \mathrm{p}<0,05 ; * * \mathrm{p}<0,01 ; * * * \mathrm{p}<0,001$.

Os resultados encontrados nesse modelo demonstram que esse conjunto de variáveis é responsável por explicar $38,4 \%$ da variância $\left(\mathrm{R}^{2}=0,384\right)$ da variável critério, autogerenciamento do desempenho. Os fatores "engajamento com o trabalho", "atração e retenção" e "mestrado" se relacionaram positivamente. Já os fatores "primeiros gestores" e "salários e oportunidades de crescimento" se correlacionaram negativamente com a variável critério analisada. Isto significa inferir que participantes do cargo de Primeiro Gestor, que afirmaram estar engajados com o trabalho e percebem positivamente a prática de retenção de talentos adotada pela Organização, porém se mostram insatisfeitos com a política de salários e oportunidades de crescimento, predizem as estratégias de autogerenciamento do desempenho.

Este resultado sinaliza que as práticas de engajamento e de retenção impactam positivamente sobre desempenho. Podem haver fatores contextuais, como os discutidos por Arvey e Murphy (1998) e Borman e Motowidlo (1997) que incentivem o vínculo do trabalhador para com sua organização. Das e Baruah (2013) afirmam que estes vínculos podem ser operacionalizados sob a forma de comprometimento afetivo e envolvimento, e tendem a promover vivências de bem-estar e satisfação com o trabalho.

De forma geral, os resultados encontrados reforçam a influência dos fatores de satisfação em relação ao desempenho, confirmando os achados encontrados por Hsieh (2016). Importante salientar o fato de que nos cinco modelos propostos, o fator "engajamento com o trabalho" manteve relações preditivas positivas com os fatores de desempenho, ao mesmo tempo que o fator "salários e oportunidades de crescimento" se relacionou negativamente em três oportunidades. Essa constatação reforça para a instituição o comprometimento dos funcionários em relação ao trabalho, ao mesmo tempo que enfatiza um grau de insatisfação no que diz respeito à política salarial e oportunidades de ascensão interna adotadas pela empresa.

A representação pictórica do modelo empírico obtido pode ser visualizada na Figura 5. 


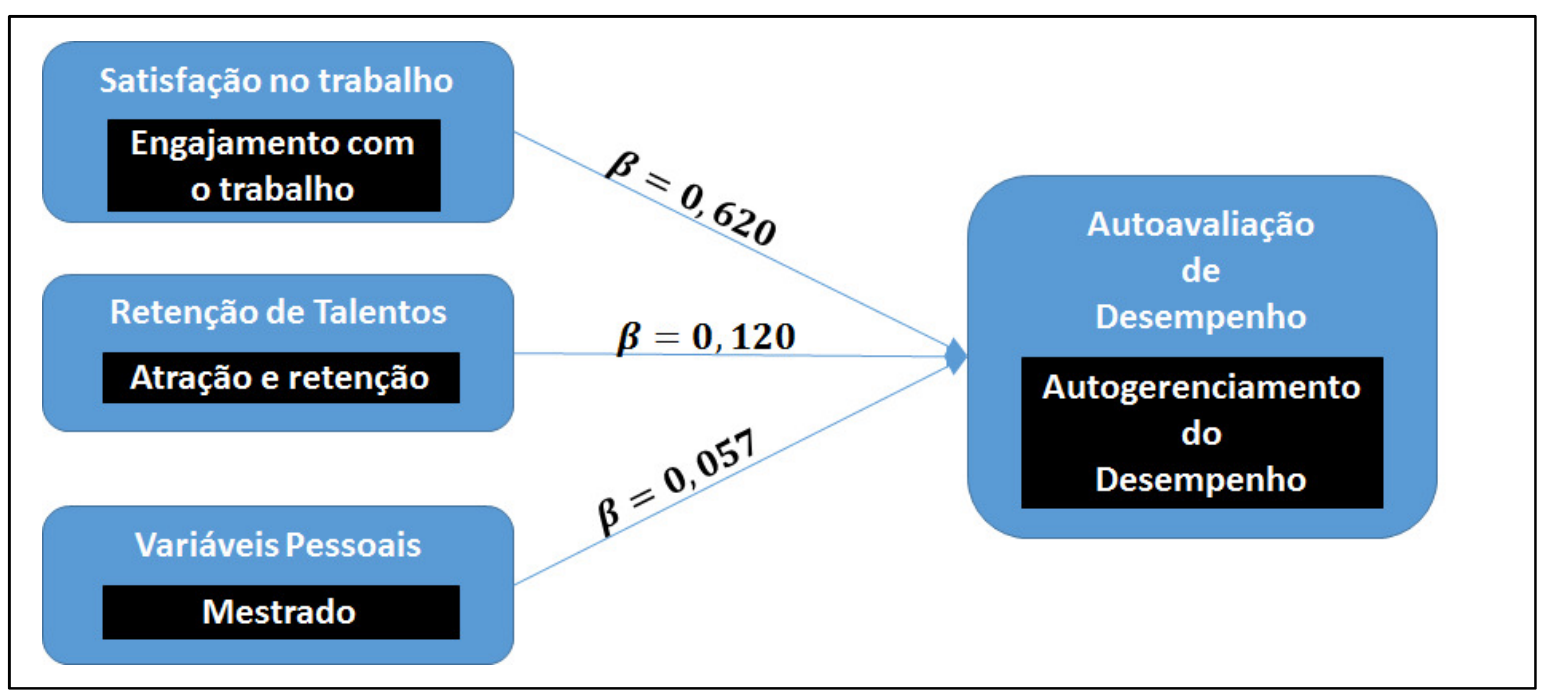

Figura 5. Modelo empírico - Fator Autogerenciamento do Desempenho Fonte: Dados da pesquisa

\subsubsection{Variável Critério: Execução, Monitoramento e Revisão de Desempenho}

No que se refere ao modelo empírico obtido com a testagem da variável critério "Execução, Monitoramento e Revisão", pode-se verificar que engajamento com o trabalho também contribuiu de forma significativa com a predição da variável critério associada $(\beta=0,40)$.

Na Tabela 13, apresentada a seguir, encontam-se os preditores empíricos para a variável critério "Execução, Monitoramento e Revisão do Desempenho".

Tabela 13

Resultados Regressão Linear - Variável Critério: Execução, Monitoramento e Revisão do Desempenho

\begin{tabular}{lcccc}
\hline \multirow{2}{*}{ Variáveis Explicativas } & \multicolumn{4}{c}{ Modelos empíricos reduzidos (Valor de $\boldsymbol{\beta}$ ) } \\
\cline { 2 - 5 } & I & II & III & IV \\
\hline Engajamento com o trabalho & 0,607 & 0,405 & 0,399 & 0,403 \\
\hline Performance de talentos & & 0,351 & 0356 & 0,353 \\
\hline Idade & & & 0,055 & 0,054 \\
\hline Superior & & & & $-0,051$ \\
\hline $\mathbf{R}^{\mathbf{2}}$ & 0,369 & 0,451 & 0,454 & 0,457 \\
\hline $\mathbf{R}^{\mathbf{2}}$ Ajustado & 0,368 & 0,450 & 0,452 & 0,454 \\
\hline $\mathbf{R}$ & $0,607^{\mathrm{a}}$ & $0,672^{\mathrm{b}}$ & $0,674^{\mathrm{c}}$ & $0,676^{\mathrm{d}}$ \\
\hline
\end{tabular}

Fonte: Dados da pesquisa

$* \mathrm{p}<0,05 ; * * \mathrm{p}<0,01 ; * * * \mathrm{p}<0,001$.

Os resultados encontrados nesse modelo demonstram que esse conjunto de variáveis é responsável por explicar $45,7 \%$ da variância $\left(R^{2}=0,457\right)$ da variável critério, execução, monitoramento e revisão do desempenho. Engajamento com o trabalho, performance de 
talentos e idade dos participantes se relacionaram positivamente com a variável critério analisada.

Importante observar o comportamento oposto das variáveis pessoais nos modelos propostos. Enquanto o fator "idade" contribuiu de forma positiva para os modelos apresentados, o fator "superior", exerceu influência negativa em relação ao desempenho, confirmando em parte os resultados encontrados por Coelho Jr e Borges Andrade (2010).

Denton (2000) também verificou que variáveis pessoais são capazes de impactar no emprego de estratégias de supervisão e análise do desempenho no trabalho. Para o autor, a análise destas características de clientela influencia diretamente na motivação dos indivíduos em situação laboral. Já Osteraker (1999), investigando dimensões de motivação, também identificou a influência de variáveis pessoais (tais como engajamento, por exemplo) na formação de vínculos com a organização.

A nível organizacional, tal constatação demonstra que à medida que os participantes envelhecem, aumenta a preocupação com o próprio desempenho. Respondentes de nível superior declararam não desenvolver continuamente estratégias de monitoramento e revisão de desempenho em comparação a participantes de maior escolaridade. Relevante constatar que o fator "engajamento com o trabalho", a exemplo dos modelos apresentados no subitem anterior, continua a se relacionar positivamente com a variável critério, corroborando a existência de relações preditivas entre as variáveis.

A representação pictórica do modelo empírico obtido pode ser visualizada na Figura 6.

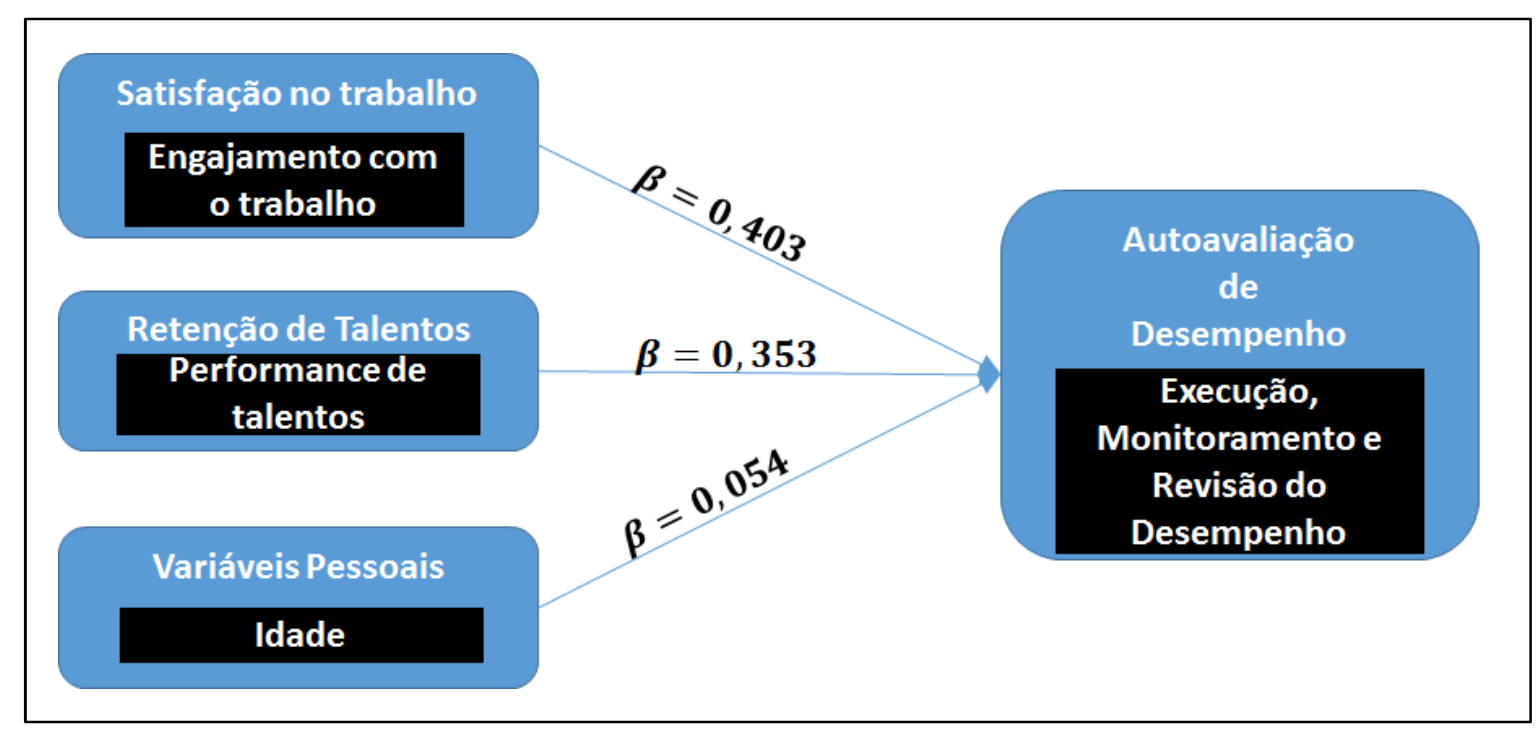

Figura 6. Modelo empírico - Fator Execução, Monitoramento e Revisão do Desempenho Fonte: Dados da pesquisa 


\subsubsection{Variável Critério: Regulação de Desempenho}

Por fim, com relação ao último modelo empírico presentemente testado, mais uma vez a variável relativa a engajamento com o trabalho demonstrou ser a principal preditora de performance (medido por meio da utilização de estratégias regulatórias de desempenho). Os resultados sintetizados são apresentados na Tabela 14.

Tabela 14

Resultados Regressão Linear - Variável Critério: Regulação do Desempenho

\begin{tabular}{lcccc}
\hline \multirow{2}{*}{ Variáveis Explicativas } & \multicolumn{4}{c}{ Modelos empíricos reduzidos (Valor de $\beta$ ) } \\
\cline { 2 - 5 } & I & II & III & IV \\
\hline Engajamento com o trabalho & 0,642 & 0,552 & 0,609 & 0,588 \\
\hline Atração e retenção & & 0,127 & 0,175 & 0,157 \\
\hline Salários e oportunidades de crescimento & & & $-0,137$ & $-0,187$ \\
\hline Performance de talentos & & & & 0,117 \\
\hline $\mathbf{R}^{2}$ & 0,412 & 0,420 & 0,429 & 0,437 \\
\hline $\mathbf{R}^{2}$ Ajustado & 0,412 & 0,419 & 0,427 & 0,434 \\
\hline $\mathbf{R}$ & $0,642^{\mathrm{a}}$ & $0,648^{\mathrm{b}}$ & $0,655^{\mathrm{c}}$ & $0,661^{\mathrm{d}}$ \\
\hline
\end{tabular}

Fonte: Dados da pesquisa

$* \mathrm{p}<0,05 ; * * \mathrm{p}<0,01 ; * * * \mathrm{p}<0,001$.

Os resultados encontrados nesse modelo demonstram que esse conjunto de variáveis é responsável por explicar $43,7 \%$ da variância $\left(R^{2}=0,437\right)$ de regulação do desempenho. Engajamento com o trabalho, percepção de efetividade das práticas de atração e retenção e performance de talentos contribuíram positivamente à predição da variável critério em análise. Satisfação quanto a "Salários e oportunidades de crescimento" contribuiu negativamente com a variável investigada. A exemplo dos modelos anteriores, nota-se claramente a influência positiva do fator "engajamento com trabalho" no que diz respeito a desempenho.

A política de remunerações adotada pela Organização não é compreendida como satisfatória por parte dos respondentes desta pesquisa. Pode ser que haja variáveis de nível contextual (por exemplo, relativas à justiça procedimental e distributiva) que estejam influenciando esta percepção. Ressalta-se que a utilização de técnicas qualitativas para a investigação das razões desta insatisfação pode auxiliar na compreensão deste fenômeno.

Em referência aos fatores de retenção, percebe-se a interferência positiva em relação aos fatores de desempenho, confirmando os achados de Lewis e Rechman (2006) e Hausknecht et al. (2009). Nos três modelos testados, houve a inserção de pelo menos um dos fatores de retenção, sejam eles "atração e retenção" ou "performance de talentos". Da mesma forma, esse fato demonstra o acerto da organização em investir nas práticas de retenção de talentos, seja pelo incentivo ao ingresso de novos funcionários ou na permanência desses profissionais na empresa 
A representação pictórica do modelo empírico obtido pode ser visualizada na Figura 7.

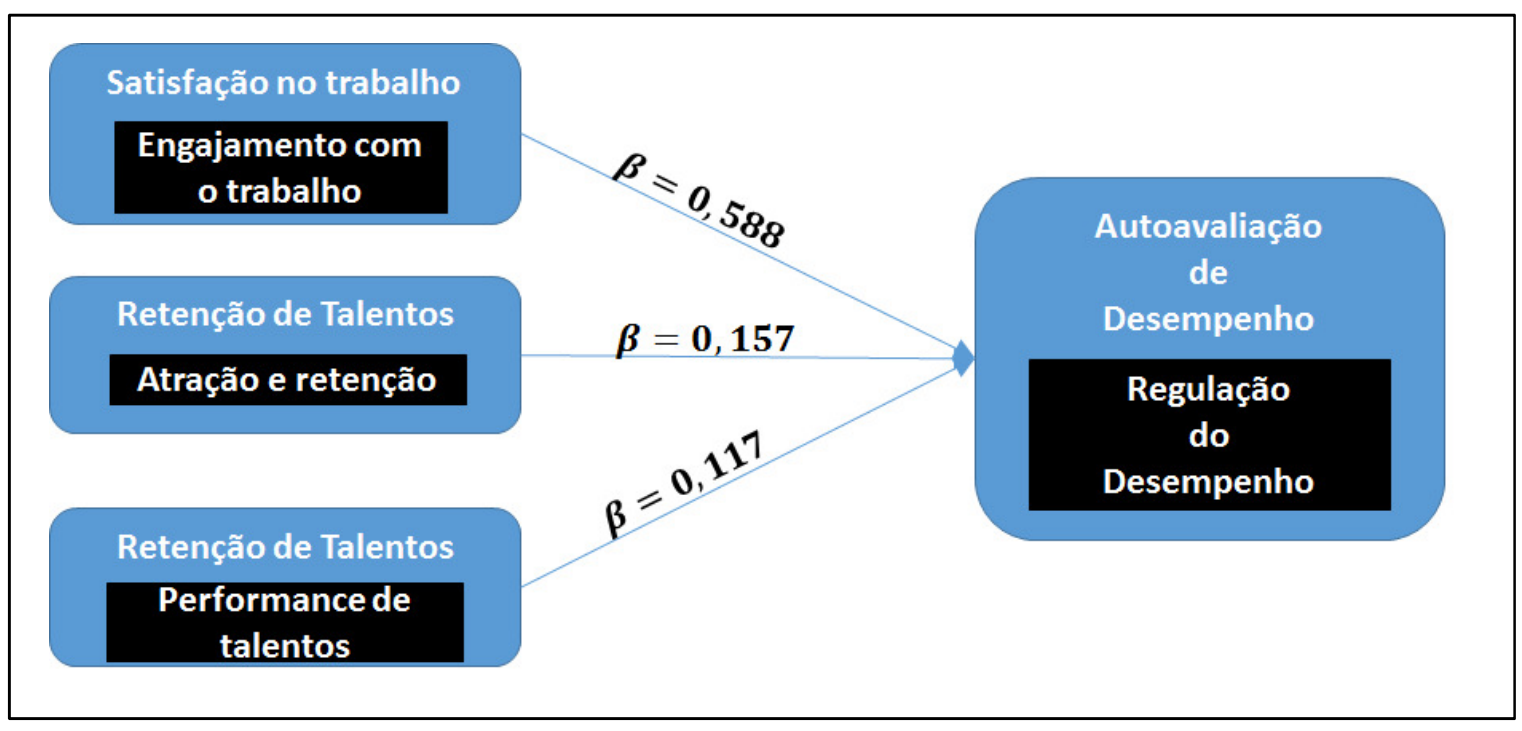

Figura 7. Modelo empírico - Fator Regulação do Desempenho Fonte: Dados da pesquisa

Em síntese, os três modelos empíricos obtidos estão sintetizados na Tabela 15.

Tabela 15

Síntese dos modelos empíricos

\begin{tabular}{|c|c|c|c|}
\hline Modelo & Variável Critério & $\mathbf{R}^{2}$ & Preditores \\
\hline I & $\begin{array}{l}\text { Autogerenciamento do } \\
\text { Desempenho }\end{array}$ & 0,384 & $\begin{array}{c}\text { Engajamento com o trabalho } \\
\text { Primeiros gestores } \\
\text { Salários e oportunidades de crescimento } \\
\text { Atração e retenção } \\
\text { Mestrado }\end{array}$ \\
\hline II & $\begin{array}{l}\text { Execução, Monitoramento e } \\
\text { Revisão do Desempenho }\end{array}$ & 0,457 & $\begin{array}{c}\text { Engajamento com o trabalho } \\
\text { Performance de talentos } \\
\text { Idade } \\
\text { Superior }\end{array}$ \\
\hline III & Regulação do Desempenho & 0,437 & $\begin{array}{c}\text { Engajamento com o trabalho } \\
\text { Atração e retenção } \\
\text { Salários e oportunidades de crescimento } \\
\text { Performance de talentos }\end{array}$ \\
\hline
\end{tabular}

Fonte: Dados da pesquisa 


\section{Conclusão}

O objetivo geral deste presente trabalho consistiu em verificar as relações empíricas entre satisfação com o trabalho, percepção de efetividade das práticas organizacionais orientadas à retenção de talentos e autoavaliação de desempenho no âmbito de uma Instituição bancária nacional. Considera-se esse objetivo foi alcançado, uma vez que foram testadas relações preditivas entre as variáveis em análise. Acredita-se, também, que os objetivos específicos foram atingidos, e a pergunta de pesquisa respondida.

A contribuição mais significativa deste trabalho foi a proposição e testagem empírica de uma medida orientada à percepção de efetividade das práticas de retenção de talentos. Poucas medidas validadas e calibradas são disponibilizadas na literatura, especialmente a nacional.

A medida validada neste estudo permitiu, ainda, a testagem de modelos empíricos preditivos, garantindo evidências de validade de construto. Em conformidade com a hipótese levantada, confirmou-se o efeito preditivo das práticas de retenção de talentos em relação a desempenho no trabalho.

Recomenda-se, para estudos futuros, e buscando validade externa, que a medida seja replicada em distintos lócus organizacionais, efetuando-se adequações semânticas quando for o caso a partir da análise da realidade de cada Organização. Mesmo assim, a calibragem da medida de retenção de talentos pode ser considerada como satisfatória em relação aos índices psicométricos obtidos.

Quanto a contribuições práticas, esta Dissertação enfatiza a necessidade de se considerar as práticas de retenção de talentos como uma importante iniciativa gerencial e da ARH, e que, para tanto, deve estar devidamente integrada e incorporada com outras práticas organizacionais. Os resultados desta pesquisa apontam o eminente êxito da Instituição estudada na promoção de ações e práticas que proporcionem um nível crescente de satisfação interna, como forma de manter o engajamento dos trabalhadores com os trabalhos a serem realizados. Apenas o fator “Gestão de Talentos” precisa ser mais profundamente investigado sob uma ótica qualitativa, de modo a compreender possíveis fontes de insatisfação que podem estar acontecendo com relação a esta prática.

Como limitações deste Estudo, destaca-se que apesar da pesquisa ter sido desenvolvida a partir de uma amostra relativamente grande $(\mathrm{N}=1.292)$, composta por indivíduos com características pessoais e profissionais diversas, os participantes deste estudo integram o lócus da mesma Organização. Isto não garante validade externa aos achados empíricos especialmente nos modelos de regressão. 
Ainda com relação aos participantes da pesquisa, a amostra foi intencional ou propositiva, não selecionada de forma aleatória ou estratificada. Esta limitação deve ser considerada para a análise dos resultados no âmbito interno, principalmente em relação à generalização dos resultados, mesmo para futuras aplicações em contextos diferentes dentro da própria Organização.

Importante salientar que, devido aos poucos estudos disponíveis envolvendo a variável "efetividade das práticas de retenção de talentos", considerou-se, para compor o modelo teórico hipotético desta pesquisa, apenas variáveis antecedentes que já foram anteriormente pesquisadas, e que tinham um mínimo de lastro teórico para explicar desempenho no trabalho.

Outra limitação a ser apontada é o uso das medidas de autorelato. Apesar dessas medidas serem amplamente aplicadas nas ciências sociais, elas estão sujeitas à interferência de fatores de vieses, como a desejabilidade social. Existem alternativas, como medidas baseadas em heteroavaliações (pares e supervisores), e testes implícitos, todavia o tempo que se dispôs para a realização deste estudo e o tamanho e a dispersão da amostra tornaram inviável a utilização conjunta de outras medidas.

Ressalta-se que mesmo com as limitações apresentadas na presente pesquisa, inerentes em grande parte à quantidade de estudos organizacionais, decorrentes de restrições de método, disponibilidade de dados e de escolhas do pesquisador, entende-se que essas questões não impediram o alcance dos objetivos desta pesquisa.

Quanto à proposição de agendas de pesquisa, para fins de estudos futuros sobre o construto "retenção de talentos", recomenda-se a aplicação de técnicas de análise conceitual, no sentido de melhor compreender, teoricamente, as propriedades axiológicas deste fenômeno. Recomenda-se, também, a realização de pesquisas com abordagem qualitativa. A análise em profundidade permite a visualização de outras dimensões ou atributos do fenômeno que poderiam vir a contribuir para uma melhor análise desta variável.

Apesar dos resultados serem específicos para a realidade da Organização estudada, a escala de retenção de talentos pode ser aplicada em populações semelhantes, em outros outras Organizações do mesmo segmento, por exemplo, a partir de ajustes no vocabulário e consequente validação em amostras específicas.

Outra medida para aplicações futuras na própria Organização, a partir do enfoque quantitativo, seria o cruzamento com outros segmentos de população de empregados (de outras áreas não presentemente investigadas) a fim de verificar se a configuração fatorial e as relações de predição obtidas em cada um dos três modelos empíricos encontrados se mantêm. 
Por fim, recomenda-se que os novos estudos a serem desenvolvidos invistam na testagem empírica da relação entre retenção de talentos e outros construtos, como bem-estar no trabalho, comprometimento e significado com o trabalho, como forma de fortalecer o conhecimento e a aumentar a produção nacional dessa variável. 


\section{Referências}

Aldamoe, F. M. A.; Yazam, M.; Ahmid, K. Bin. The Mediating Effect of HRM Outcomes (employee retention) on the Relationship between HRM Practices and Organization Performance. International Journal of Human Resource Studies, v. 2, n.1, p. 75-88, 2011.

Allen, D.; Bryant, P.; Vardaman, J. Retaining talento: Replacing misconceptions with evidencebased strategies. Academy of Management Perspectives, v. 24, n.2, p. 48-65, 2010.

Almeida, Walnice. Captação e seleção de talentos: Repensando a teoria e a prática. São Paulo: Atlas, 2004.

Arvey, R. D., \& Murphy, K. R. (1998). Performance evaluation in work settings. Annual Review of Psychology, 49(1), 141-168.

Banco do Brasil - Rede de Atendimento - Recuperado em 01 de abril de 2016, de http://www.bb.com.br/portalbb.

Bardin L. Análise de Conteúdo. 5.ed. Lisboa: Ed 70; 2009.

Bendassolli, P. F. (2012). Desempenho no trabalho: Revisão da literatura. Psicologia argumento, 30(68), 171-184.

Berger, L.; Berger, D. The Talent Management Handbook: Creating Organizational Excellence by Identifying, Developing, and Promoting Your Best People. New York: McGraw-Hill, 2004.

Bernthal, P.; Wellins, R. Retaining talent: a benchmarking stydy. Pittsburgh: Development Dimensions International, 2001.

Bethke-Langenegger, P. The Differentiated Workforce - Effects of Categorisation in Talent Management on Workforce Level. Zurique: Universidade de Zurique, 2012.

Borman, W. C., \& Motowidlo, S. M. (1997). Task performance and contextual performance: The meaning for personnel selection. Human Performance, 10, 99-109.

Brunetto Y, Farr-Wharton R (2002). "Using social identity theory to explain the job satisfaction of public sector employees”. International Journal of Public Sector Manage, 15 (7): 534-551.

Camões, M. R. S. (2013). Análise do processo de implementação da Política Nacional de Desenvolvimento de Pessoal (Dissertação de mestrado). Universidade de Brasília, Brasília, DF, Brasil.

Campbell, J.P. (1990). Modeling the performance prediction problem in industrial and organizational psychology. In: M. D. Dunnette \& L. M. Hough (Eds.), Handbook of Industrial and Organizational Pychology. Palo Alto: Consulting Pychologists Press.

Caracol, C. C., Palma, P. J. D., Lopes, M. P., \& Sousa, M. J. (2016). Gestão estratégica do talento na perspectiva individual e organizacional: proposta de modelo. Revista Psicologia Organizações e Trabalho, 16(1), 10-21.

Cardy, R. L.; Lengnick-Hall, M. L. Will They Stay Exploring a Customer-Oriented Approach To Employee Retention. Journal of Buseness and Psychology, v.26, n.2, p. 213-217, 2011. 
Cervo, A. L.; Bervian, P. A.; Da Silva, R. Metodologia Científica. 6. ed. São Paulo: Pearson Prentice Hall, 2007.

Coelho Jr., F. A. (2009). Suporte à aprendizagem, satisfação no trabalho e desempenho: Um estudo multinível. Tese de doutorado não publicada, Instituto de Psicologia, Universidade de Brasília, Brasília.

Coelho Jr., F. A., Borges-Andrade, J. E., Oliveira, J. S., \& Pereira, A. C. (2010). Validação psicométrica de medida de auto-avaliação de desempenho no trabalho. Anais. XXXIV Encontro da Anpad (Enanpad), Rio de Janeiro.

Collins, D. G., \& Mellahi, K. (2009). Strategic Talent Management: A Review and Research Agenda, Human resource management review. 19 (4), 304-313.

Da Silva Barreto, L. M. T., da Silva, M. P., Fischer, A. L., de Albuquerque, L. G., \& de Amorim, W. A. C. (2011). Temas emergentes em gestão de pessoas: uma análise da produção acadêmica. Revista de Administração da UFSM, 4(2), 215-232.

Das, B.L.; Baruah, M. (2013). Employee Retention: A Review of Literature. OSR Journal of Business and Management (IOSR-JBM), 14(2), 8-16.

Denton, J. (2000), "Using Web-based projects in a systems design and development course". Journal of Computer Information Systems, Vol. 40 n.3, pp.85-87.

Dipietro, R.; Thozhur, S.; Milman, A. Hourly employee retention factors in the United Kington quick service restaurant industry. Journal of Foodservice Business Research, v.10, n.4, p. 3961, 2007.

Everlin, D. The influence of global talento management on employer attractiveness: Na experimental study. Zeitschrift für Personalforchung, v.27, n.3, p. 279-304, 2013.

Field, A. (2009). Descobrindo a Estatística usando o SPSS (2 ed.). (L. Viali, Trad.) Porto Alegre: Artmed.

Figueiredo Filho, D. B., \& Silva Júnior, J. A. D. (2010). Visão além do alcance: uma introdução à análise fatorial. Opinião Pública, 16(1), 160-185.

Fishman, C. (1998). The war for talent. Fast Company, 16, n.1, p. 104-108.

Fogaça, N., Rego, M. C. B., Armond, L. P., \& Mendonça, J. M. B. (2016). Job performance: scenario of scientific production between 2011 to 2015. Anais. XXI Conference of International Academy of Business and Management (IAMB), Montreal.

Freitag, B. B. (2012). Talentos em Gestão e Gestão de Talentos: Análise da Literatura Acadêmica e de Práticas Corporativas (Doctoral dissertation, Universidade de São Paulo)

Gaertner, K. N.; Nollen, S. D. Turnover Intentions and Desire Among Executives. Human Relations, v. 45, n. 5, p. 447-465, 1992.

Gallardo-Gallardo, E., Dries, N., \& González-Cruz, T. F. What is the meaning of 'talent' in the world of work?. Human Resource Management Review, 23(4), 290-300, 2013. 
Gayathri, R.; Sivaraman, G.; e Kamalambal, R. Employee retention strategies in BPO'S - An Empirical Investigation. Interdisciplinary Journal of Contemporary Research in Business, V. 3, n.12, p. 572-584, 2012.

Gil, A.C. Métodos e técnicas de pesquisa social. São Paulo: Atlas, 2008.

Griffeth, R. W. et. al. The Development of a multidimensional measure of job Market cognitions: the Employment Opportunity Index (EOI). The Journal os Applied psychology, v. 90, n. 2, p. 335-49, 2005.

Hair Jr., J. F., Black, W. C., Babin, B. J., Anderson, R. E., \& Tatham, R. L. (2006). Análise Multivariada de Dados. Porto Alegre: Bookman.

Hausknecht, J.; Rodda, J.; Howard, M. J. Targeted employee retention: Performance - based and job - related differences in reported reasons for staying. Human Resource Management, v. 48, n. 2, p. $269-288,2009$.

Hilthrop, J. (1999). The quest for the best: Human resource practices to attract and retain talent. European Management Journal, 17(4),422-430. doi: 10.1016/S0263-2373(99)00022-5

Hsieh, J. Y. (2016). Spurious or true? An exploration of antecedents and simultaneity of job performance and job satisfaction across the sectors. Public Personnel Management, 45(1), 90118.

Hulin, C. L.; Smith, P.C. A Linear Model of Job Satisfacion. Journal of Appied Psychology, v. 49, n.3, p. 2009-16, 1965.

Iles, P., Preece, D., \& Chuai, X. (2010). Talent management as a management fashion in HRD: Towards a research agenda. Human Resource Development International, 13(2),125-145. doi: $10.1080 / 13678861003703666$

Jackson, S. E.; Schuler, R. S. Human resource planning: Challenges for industrial/organization psychologists. American Psychologist, v.45, n.2, p. 223-239, 1990.

Kontoghiorghes, C. \& Frangou, K. The association between talent retention, antecedent factors and consequent organizational performance. SAM Advanced Management Journal, 74(1), 29-58, 2009.

Lacombe, B. M. B., \& Tonelli, M. J. (2001). O discurso e a prática: o que nos dizem os especialistas e o que nos mostram as práticas das empresas sobre os modelos de gestão de recursos humanos. Revista de Administração Contemporânea, 5(2), 157-174.

Lewis, R. E., \& Heckman, R. J. (2006). Talent management: A critical review. Human Resource Management Review, 16(2),139-154. doi: 10.1016/j.hrmr.2006.03.001

Lucena, M. D. S. (1992). Avaliação de Desempenho. São Paulo: Atlas.

Lundell, H., Niederdeppe, J., \& Clarke, C. (2013). Public views about health causation, attributions of responsibility, and inequality. Journal of health communication, 18(9), 1116-1130.

Marinho, M. S. C. Satisfação no trabalho: uma revisão conceitual para a análise empírica. Ciência e Cultura, v. 40, n. 3, p. 312-322, 1988. 
Martinez, M. C. As relações entre a satisfação com aspectos psicossociais no trabalho e a saúde do trabalhador. 2002. 255 f. Dissertação (Mestrado em Saúde Ambiental) - Faculdade de Saúde Pública da Universidade de São Paulo.

Martinsa, V., Costa, L. V., \& Siqueira, M. M. M. (2016). O impacto do comprometimento afetivo e do engajamento no trabalho sobre os comportamentos de cidadania organizacional. Revista de Administração, Contabilidade e Economia da Fundace, 6(2)

Mattar, F. N. Pesquisa de Marketing - Edição Compacta. 3. ed. São Paulo: Atlas, 2001.

McClelland, D. C. et al. Talent and society: New perspectives in the identification of talent. New Jersey: D Van Nostrand Company, (1958).

Mello, D. A. D. (2014). Análise dos fatores de retenção de empregados em organizações que atuam no Brasil (Doctoral dissertation, Universidade de São Paulo).

Mendonça, Márcia da Costa Furtado de. Retenção de Talentos por Meio de Reconhecimento e Recompensa. Dissertação de Mestrado apresentada à Escola Brasileira de Administração Pública, Centro de Formação Acadêmica e Pesquisa, Curso de Mestrado Executivo Fundação Getúlio Vargas - FGV, São Paulo, 2002.

Meyers, M. C.; Van Woerkom, M.; Dries, N. Talent - Innate or acquired? Thoretical Considerations and their implications for talento management. Human Resource Management Review, v. 23, n.4, p. 305-321, 2013.

Michaels, Ed ; Handfield-JONES, Helen; Axelrod, Beth. A guerra pelo talento: o talento como diferencial estratégico entre as empresas. Rio de Janeiro: Ed. Campus, 2002.

Milkovich Newman, (2004) Compensation. The McGraw-Hill Companies.

Moynihan, D. P., \& Pandey, S. K. (2010). The big question for performance management: Why do managers use performance i nformation. Journal of public administration research and theory.

Organização para a Cooperação e Desenvolvimento Econômico. (2002). Des politiques de développment basées sur les aménités rurales: Guide pour l'action publique. OCDE publication, Paris, 2002.

Osteraker, M.C. (1999). Measuring motivation in a learning organization. Journal of WorkPlace Learning.

Pasquali, L. (2010). Testes referentes a construto: teoria e modelo de construção. Em L. e. Pasquali, Instrumentação Psicológica: fundamentos e práticas. Porto Alegre: Artmed.

Porter, L. W.; Steers, R. M. Organizational, work, and personal factors in employee turnover and absenteeism. Psychological Bulletin, v. 80, p. 151-176, 1973.

Ramesh, A.; Gelfand, M. J. Will they stay or will they go? The role of job embeddedness in predicting turnover in individualistic and collectivistic cultures. The Journal of Applied psychology, v. 95, n. 5, p. 87-23, 2010.

Ramlall, S. (2003). Managing Employee Retention as a Strategy for Increasing Organizational Competitiveness, Applied H.R.M. Research, 8(2), 63-72. 
Riza, S. D., Ganzach, Y., \& Liu, Y. (2016). Time and Job Satisfaction A Longitudinal Study of the Differential Roles of Age and Tenure. Journal of Management, 0149206315624962.

Sampieri, R. H., Collado, C. F., \& Lucio, P. B. (2006). Metodologia de Pesquisa. São Paulo: McGraw Hill.

Simpson, M. R. Engagement at Work: A review of the literature. International Journal of Nursing Studies, v. 46, p. 1012-1024, 2009.

Siqueira, M. M. M. Antecedentes de comportamento de cidadania organizacional: análise de um modelo pós-cognitivo. 1995. 267 p. Tese (Doutorado em Psicologia) - Instituto de Psicologia da Universidade de Brasília, Brasília, 1995.

Siqueira, M. M. M. Satisfação no trabalho. In SIQUEIRA, M. M. M. (Org.). Medidas do Comportamento Organizacional: ferramentas de diagnóstico e de Gestão. Porto Alegre: Artmed, 2008. P. 265-275.

Siqueira, M. M. M.; Gomide Júnior, S. Vínculos do indivíduo com o trabalho e com a organização. In: Zanelli, J. C.; Borges-Andrade, J. E.; Bastos, A. V. B. (Orgs.). Psicologia, organizações e trabalho no Brasil. Porto Alegre: Artmed, 2004. p. 300-328.

Sonnentag, S.; Frese, M. (2002). Performance concepts and performance theory. Em S. Sonnentag (Org.), Psychological management of individual performance (p.03-25). Chichester, UK: John Wiley \& Sons.

Steil, A. V., Penha, M. M., \& Bonilla, M. A. M. Antecedentes da retenção de pessoas em organizações: uma revisão de literatura. Revista Psicologia Organizações e Trabalho, 16(1), 88-102, 2016.

Sullivan, S. E., \& Baruch, Y. (2009). Advances in career theory and research: A critical review and agenda for future exploration. Journal of management, 35(6),1542-1571. doi: $10.1177 / 0149206309350082$.

Tabachnick, B. G., \& Fidell, L. S. (2007). Using multivariate statistics. New York: Harper \& Row Collins College Publishers.

Talentdrain. The Employee Retention Survey 2008 - Dispelling the Myths Surrounding Retention. Londres: TalentDrain, 2008.

Tamayo, A. Prioridades axiológicas e satisfação no trabalho. Revista de Administração da Universidade de São Paulo, 35(2), 2000.

Tansley, C. What do we mean by the term "talent" in talent management?. Industrial and commercial training, 43(5), 266-274, 2011.

Thunnissen, M., Boselie, P., \& Fruytier, B. (2013). Talent management and the relevance of context: Towards a pulralistic approach. Human Resource Management Review, 23(4),326-336. doi: 10.1016/j.hrmr.2013.05.004

Ulrich, D. Recursos humanos estratégicos: novas perspectivas para os profissionais de RH. São Paulo: Futura, 2000. 
Ulrich, D. The talento trifecta. Workforce Mangement, v.86, n.15, p. 32-33, 2007.

Ulrich, D., \& Smallwood, N. (2012). What is talent? Leader to Leader, 2012(63),55-61.

Valle, Â. D. R. (2009). Monitoramento da satisfação no trabalho em uma empresa financeira. Tese de doutorado, Universidade de Brasília, Brasília.

Wells, M., \& Thelen, L. (2002) "What does your workspace say about you? The influence of personality, status and workspace on personalization. Environment and Behavior, 3: 300. 


\section{Anexos}

\subsection{Medida de Autoavaliação de Desempenho no Trabalho}

Coelho Jr., Borges Andrade, Oliveira \& Pereira (sem data)

Prezado (a) Participante,

Este questionário visa identificar sua percepção sobre seu desempenho no exercício de suas tarefas e atribuições.

Sua tarefa consiste em ler e avaliar cada um dos itens que lhe for apresentado (a). A escala varia de 1 (discordo totalmente com a afirmativa do item) a 10 (concordo totalmente com a afirmativa do item).

Não existe resposta certa ou errada. Sua resposta deve exprimir exatamente o que você pensa sobre cada afirmativa. Por favor, procure não deixar nenhuma questão em branco. Escolha qualquer ponto da escala que melhor lhe convier, de acordo com sua análise e julgamento da afirmativa.

Sua contribuição é de extrema valia à realização deste trabalho. Por favor, seja sincero ao dar suas respostas. Os dados serão analisados conjuntamente, não individualmente. O sigilo das suas respostas está totalmente garantido.

Obrigada, desde já, pela sua importante participação nesta pesquisa!

Qualquer dúvida, favor contatar ...

\begin{tabular}{|c|c|c|}
\hline \multicolumn{3}{|c|}{ Primeiro Fator: Regulação do Desempenho } \\
\hline 1. & $\begin{array}{l}\text { Faço minhas tarefas procurando manter compromisso com esta } \\
\text { Organização. }\end{array}$ & $\begin{array}{l}\text { (1) (2) (3) (4) (5) } \\
\text { (6) (7) (8) (9) (11) }\end{array}$ \\
\hline 2. & $\begin{array}{l}\text { Avalio que o desempenho do meu trabalho contribui diretamente para a } \\
\text { consecução da missão e objetivos desta Organização. }\end{array}$ & $\begin{array}{l}\text { (1) (2) (3) (4) (5) } \\
\text { (6) (7) (8) (9) (11) }\end{array}$ \\
\hline 3. & $\begin{array}{l}\text { Comprometo-me com as metas e objetivos estabelecidos pela } \\
\text { Organização. }\end{array}$ & $\begin{array}{l}\text { (1) (2) (3) (4) (5) } \\
\text { (6) (7) (8) (9) (II) }\end{array}$ \\
\hline 4. & $\begin{array}{l}\text { Redireciono minhas ações em meu trabalho em razão de mudanças nos } \\
\text { objetivos desta Organização. }\end{array}$ & $\begin{array}{l}\text { (1) (2) (3) (4) (5) } \\
\text { (6) (7) (8) (9) (11) }\end{array}$ \\
\hline
\end{tabular}




\begin{tabular}{|c|c|c|}
\hline 5. & Meu trabalho é importante para o desempenho desta Organização. & $\begin{array}{l}\text { (1) (2) (3) (4) (5) } \\
\text { (6) (7) (8) (9) (11) }\end{array}$ \\
\hline 6. & $\begin{array}{l}\text { Mantenho-me atualizado quanto ao conhecimento técnico em minha área } \\
\text { de atuação. }\end{array}$ & $\begin{array}{l}\text { (1) (2) (3) (4) (5) } \\
\text { (6) (7) (8) (9) (11) }\end{array}$ \\
\hline 7. & $\begin{array}{l}\text { Mantenho um canal permanente de comunicação, favorecendo a } \\
\text { interação com outras pessoas. }\end{array}$ & $\begin{array}{l}\text { (1) (2) (3) (4) (5) } \\
\text { (6) (7) (8) (9) (11) }\end{array}$ \\
\hline 8. & $\begin{array}{l}\text { Direciono minhas ações para realizar o meu trabalho com economia de } \\
\text { recursos. }\end{array}$ & $\begin{array}{l}\text { (1) (2) (3) (4) (5) } \\
\text { (6) (7) (8) (9) (11) }\end{array}$ \\
\hline 9. & $\begin{array}{l}\text { Implemento ações mais adequadas quando detecto algum erro ou falha } \\
\text { em meu trabalho. }\end{array}$ & $\begin{array}{l}\text { (1) (2) (3) (4) (5) } \\
\text { (6) (7) (8) (9) (11) }\end{array}$ \\
\hline 10. & $\begin{array}{l}\text { Eu sei o que é esperado de mim em termos de meu desempenho no } \\
\text { trabalho. }\end{array}$ & $\begin{array}{l}\text { (1) (2) (3) (4) (5) } \\
\text { (6) (7) (8) (9) (11) }\end{array}$ \\
\hline 11 & $\begin{array}{l}\text { Tomo iniciativas, aproveitando oportunidades que possam gerar a } \\
\text { melhoria dos resultados. }\end{array}$ & $\begin{array}{l}\text { (1) (2) (3) (4) (5) } \\
\text { (6) (7) (8) (9) (11) }\end{array}$ \\
\hline 12. & $\begin{array}{l}\text { Meu desempenho no trabalho está de acordo com aquilo que é esperado } \\
\text { de mim. }\end{array}$ & $\begin{array}{l}\text { (1) (2) (3) (4) (5) } \\
\text { (6) (7) (8) (9) (11) }\end{array}$ \\
\hline \multicolumn{3}{|c|}{ Segundo Fator: Grau de Esforço e Conhecimento da Tarefa } \\
\hline 13. & $\begin{array}{l}\text { As tarefas que me são destinadas exigem que eu me esforce muito para } \\
\text { realizá-las. }\end{array}$ & $\begin{array}{l}\text { (1) (2) (3) (4) (5) } \\
\text { (6) (7) (8) (9) (11) }\end{array}$ \\
\hline 14. & $\begin{array}{l}\text { Recebo orientações adequadas à realização das tarefas sob minha } \\
\text { responsabilidade. }\end{array}$ & $\begin{array}{l}\text { (1) (2) (3) (4) (5) } \\
\text { (6) (7) (8) (9) (11) }\end{array}$ \\
\hline 15. & $\begin{array}{l}\text { Direciono minhas ações a partir do conhecimento da estrutura e das } \\
\text { políticas da empresa. }\end{array}$ & $\begin{array}{l}\text { (1) (2) (3) (4) (5) } \\
\text { (6) (7) (8) (9) (11) }\end{array}$ \\
\hline \multicolumn{3}{|c|}{ Terceiro Fator: Execução, Monitoramento e Revisão de Desempenho } \\
\hline 16. & $\begin{array}{l}\text { Contribuo com alternativas para solução de problemas e melhoria de } \\
\text { processos desta Organização. }\end{array}$ & $\begin{array}{l}\text { (1) (2) (3) (4) (5) } \\
\text { (6) (7) (8) (9) (11) }\end{array}$ \\
\hline 17. & $\begin{array}{l}\text { Estabeleço intercâmbio com outras equipes ou unidades, quando } \\
\text { necessário, para garantir o atingimento dos objetivos organizacionais. }\end{array}$ & $\begin{array}{l}\text { (1) (2) (3) (4) (5) } \\
\text { (6) (7) (8) (9) (11) }\end{array}$ \\
\hline 18. & $\begin{array}{l}\text { São realizados encontros e reuniões grupos entre mim e meus } \\
\text { colegas/pares e chefia para discussão e avaliação das ações e tarefas } \\
\text { realizadas. }\end{array}$ & $\begin{array}{l}\text { (1) (2) (3) (4) (5) } \\
\text { (6) (7) (8) (9) (11) }\end{array}$ \\
\hline 19. & $\begin{array}{l}\text { Percebo o impacto de minhas ações e do resultado do meu trabalho sobre } \\
\text { as outras áreas desta Organização. }\end{array}$ & $\begin{array}{l}\text { (1) (2) (3) (4) (5) } \\
\text { (6) (7) (8) (9) (11) }\end{array}$ \\
\hline
\end{tabular}

Continua 
Conclusão

\begin{tabular}{|c|c|c|}
\hline \multicolumn{3}{|c|}{ Quarto Fator: Autogerenciamento de Desempenho } \\
\hline 20. & $\begin{array}{l}\text { Avalio satisfatoriamente o meu desempenho na consecução de tarefas e } \\
\text { rotinas relacionadas ao meu trabalho. }\end{array}$ & $\begin{array}{l}\text { (1) (2) (3) (4) (5) } \\
\text { (6) (7) (8) (9) (11) }\end{array}$ \\
\hline 21. & $\begin{array}{l}\text { Desenvolvo o meu trabalho de acordo com os padrões e normas } \\
\text { estabelecidos. }\end{array}$ & $\begin{array}{l}\text { (1) (2) (3) (4) (5) } \\
\text { (6) (7) (8) (9) (111) }\end{array}$ \\
\hline 22. & $\begin{array}{l}\text { Utilizo ferramentas e materiais disponíveis para a melhoria dos } \\
\text { resultados de meu trabalho. }\end{array}$ & $\begin{array}{l}\text { (1) (2) (3) (4) (5) } \\
\text { (6) (7) (8) (9) (110) }\end{array}$ \\
\hline 23. & Planejo ações de acordo com minhas tarefas e rotinas organizacionais. & $\begin{array}{l}\text { (1) (2) (3) (4) (5) } \\
\text { (6) (7) (8) (9) (11) }\end{array}$ \\
\hline 24. & Adapto-me a alterações ocorridas nas minhas rotinas de trabalho. & $\begin{array}{l}\text { (1) (2) (3) (4) (5) } \\
\text { (6) (7) (8) (9) (11) }\end{array}$ \\
\hline 25. & $\begin{array}{l}\text { Estabeleço prioridades em meu trabalho, definindo ações, prazos e } \\
\text { recursos necessários. }\end{array}$ & $\begin{array}{l}\text { (1) (2) (3) (4) (5) } \\
\text { (6) (7) (8) (9) (11) }\end{array}$ \\
\hline 26. & Estabeleço a relação entre a origem e a finalidade do meu trabalho. & $\begin{array}{l}\text { (1) (2) (3) (4) (5) } \\
\text { (6) (7) (8) (9) (11) }\end{array}$ \\
\hline 27. & $\begin{array}{l}\text { Avalio que a busca pela melhoria de meu desempenho me motiva a tentar } \\
\text { fazer um trabalho melhor. }\end{array}$ & $\begin{array}{l}\text { (1) (2) (3) (4) (5) } \\
\text { (6) (7) (8) (9) (111) }\end{array}$ \\
\hline
\end{tabular}




\subsection{Pesquisa de satisfação interna no trabalho}

Valle, Ângela de Rocha (2007)

Prezado (a) Participante,

Este questionário visa identificar sua percepção sobre satisfação com o trabalho.

Sua tarefa consiste em ler e avaliar cada um dos itens que lhe for apresentado (a). A escala varia de 1 (discordo totalmente com a afirmativa do item) a 10 (concordo totalmente com a afirmativa do item).

\begin{tabular}{|c|c|c|}
\hline \multicolumn{3}{|c|}{ Engajamento com o trabalho } \\
\hline 1. & Estou satisfeito(a) com meu trabalho. & $\begin{array}{l}\text { (1) (2) (3) (4) (5) } \\
\text { (6) (7) (8) (9) (11) }\end{array}$ \\
\hline 2. & Tenho orgulho de trabalhar nesta Empresa. & $\begin{array}{l}\text { (1) (2) (3) (4) (5) } \\
\text { (6) (7) (8) (9) (11) }\end{array}$ \\
\hline 3. & $\begin{array}{l}\text { Considero relevantes as contribuições que o meu trabalho traz para a } \\
\text { sociedade. }\end{array}$ & $\begin{array}{l}\text { (1) (2) (3) (4) (5) } \\
\text { (6) (7) (8) (9) (11) }\end{array}$ \\
\hline 4. & Executo tarefas diversificadas em meu trabalho. & $\begin{array}{l}\text { (1) (2) (3) (4) (5) } \\
\text { (6) (7) (8) (9) (11) }\end{array}$ \\
\hline 5. & Compartilho dos valores disseminados pela minha empresa. & $\begin{array}{l}\text { (1) (2) (3) (4) (5) } \\
\text { (6) (7) (8) (9) (11) }\end{array}$ \\
\hline 6. & O meu trabalho é fonte de inspiração para mim. & $\begin{array}{l}\text { (1) (2) (3) (4) (5) } \\
\text { (6) (7) (8) (9) (11) }\end{array}$ \\
\hline 7. & Sinto-me motivado e entusiasmado com o trabalho que realizo. & $\begin{array}{l}\text { (1) (2) (3) (4) (5) } \\
\text { (6) (7) (8) (9) (11) }\end{array}$ \\
\hline 8. & Utilizo amplamente meus conhecimentos em meu trabalho. & $\begin{array}{l}\text { (1) (2) (3) (4) (5) } \\
\text { (6) (7) (8) (9) (11) }\end{array}$ \\
\hline 9. & Ponho em prática minhas habilidades e capacidades no trabalho. & $\begin{array}{l}\text { (1) (2) (3) (4) (5) } \\
\text { (6) (7) (8) (9) (11) }\end{array}$ \\
\hline 10. & Meu trabalho tem significado pessoal para mim. & $\begin{array}{l}\text { (1) (2) (3) (4) (5) } \\
\text { (6) (7) (8) (9) (11) }\end{array}$ \\
\hline 11. & Sinto-me parte desta empresa. & $\begin{array}{l}\text { (1) (2) (3) (4) (5) } \\
\text { (6) (7) (8) (9) (11) }\end{array}$ \\
\hline
\end{tabular}

Continua 


\section{Conclusão}

\begin{tabular}{|c|c|c|}
\hline \multicolumn{3}{|c|}{ Salários e oportunidades de crescimento } \\
\hline 12. & $\begin{array}{l}\text { Recebo um salário compatível com a responsabilidade que me é } \\
\text { conferida. }\end{array}$ & $\begin{array}{l}\text { (1) (2) (3) (4) (5) } \\
\text { (6) (7) (8) (9) (11) }\end{array}$ \\
\hline 13. & $\begin{array}{l}\text { O meu salário é compatível com os valores pagos para a minha função } \\
\text { no mercado financeiro. }\end{array}$ & $\begin{array}{l}\text { (1) (2) (3) (4) (5) } \\
\text { (6) (7) (8) (9) (11) }\end{array}$ \\
\hline 14. & $\begin{array}{l}\text { Trabalhando nesta empresa, terei oportunidade de fazer carreira e } \\
\text { crescer. }\end{array}$ & $\begin{array}{l}\text { (1) (2) (3) (4) (5) } \\
\text { (6) (7) (8) (9) (11) }\end{array}$ \\
\hline 15. & $\begin{array}{l}\text { Identifico as oportunidades de ascensão profissional existentes na } \\
\text { Empresa. }\end{array}$ & $\begin{array}{l}\text { (1) (2) (3) (4) (5) } \\
\text { (6) (7) (8) (9) (11) }\end{array}$ \\
\hline 16. & A ascensão no Banco acontece por mérito e competência & $\begin{array}{l}\text { (1) (2) (3) (4) (5) } \\
\text { (6) (7) (8) (9) (11) }\end{array}$ \\
\hline
\end{tabular}




\section{Apêndice}

\section{1 - Percepção das Políticas e Práticas de Retenção de Talentos}

Prezado(a) Participante,

Este questionário visa identificar sua percepção sobre as políticas e práticas de retenção de talentos no Banco do Brasil.

Avalie cada item, com a escala abaixo, indicando o quanto você concorda ou discorda de cada um deles, escolhendo o número de (1 a 10) que melhor reflete a sua opinião. A escala varia de 1 (discordo totalmente com a afirmativa do item) a 10 (concordo totalmente com a afirmativa do item).

Sua contribuição é de extrema importância para este trabalho. Por favor, seja sincero ao dar suas respostas. Os dados serão analisados conjuntamente, não individualmente. O sigilo das suas respostas está totalmente garantido.

Por favor, não deixe nenhum item em branco!

\begin{tabular}{|c|c|c|}
\hline 1. & $\begin{array}{l}\text { Considero que os programas de ascensão oferecidos pelo Banco } \\
\text { (Trainees, Primeiros Gestores, Programa Executivos) contribuem } \\
\text { para a retenção de talentos na Empresa. }\end{array}$ & $\begin{array}{l}\text { (1) (2) (3) (4) (5) } \\
\text { (6) (7) (8) (9) (11) }\end{array}$ \\
\hline 2. & $\begin{array}{l}\text { Em minhas atividades, tenho oportunidade de implementar projetos } \\
\text { em conjunto com outras áreas do Banco. }\end{array}$ & $\begin{array}{l}\text { (1) (2) (3) (4) (5) } \\
\text { (6) (7) (8) (9) (11) }\end{array}$ \\
\hline 3. & $\begin{array}{l}\text { As ferramentas colaborativas disponibilizadas pelo Banco (Pensa e } \\
\text { Construção) possibilitam a descoberta de novos talentos. }\end{array}$ & $\begin{array}{l}\text { (1) (2) (3) (4) (5) } \\
\text { (6) (7) (8) (9) (11) }\end{array}$ \\
\hline 4. & Meu ambiente de trabalho estimula o desenvolvimento de talentos. & $\begin{array}{l}\text { (1) (2) (3) (4) (5) } \\
\text { (6) (7) (8) (9) (111) }\end{array}$ \\
\hline 5. & $\begin{array}{l}\text { A solidez da marca "Banco do Brasil" foi importante na minha } \\
\text { decisão de ingressar na empresa. }\end{array}$ & $\begin{array}{l}\text { (1) (2) (3) (4) (5) } \\
\text { (6) (7) (8) (9) (11) }\end{array}$ \\
\hline 6. & $\begin{array}{l}\text { Os programas de benefícios influenciam na minha vontade de } \\
\text { permanecer no Banco. }\end{array}$ & $\begin{array}{l}\text { (1) (2) (3) (4) (5) } \\
\text { (6) (7) (8) (9) (11) }\end{array}$ \\
\hline 7. & $\begin{array}{l}\text { O estilo de liderança praticado no Banco valoriza os talentos do } \\
\text { corpo funcional. }\end{array}$ & $\begin{array}{l}\text { (1) (2) (3) (4) (5) } \\
\text { (6) (7) (8) (9) (11) }\end{array}$ \\
\hline 8. & O Banco oferece oportunidades para o aproveitamento de talentos. & $\begin{array}{l}\text { (1) (2) (3) (4) (5) } \\
\text { (6) (7) (8) (9) (11) }\end{array}$ \\
\hline 9. & $\begin{array}{l}\text { Reconheço que o Banco do Brasil é uma boa empresa para se } \\
\text { trabalhar. }\end{array}$ & $\begin{array}{l}\text { (1) (2) (3) (4) (5) } \\
\text { (6) (7) (8) (9) (11) }\end{array}$ \\
\hline
\end{tabular}


Conclusão

\begin{tabular}{|c|c|c|}
\hline 10. & $\begin{array}{l}\text { As políticas de retenção de talentos são uma realidade no Banco do } \\
\text { Brasil. }\end{array}$ & $\begin{array}{l}\text { (1) (2) (3) (4) (5) } \\
\text { (6) (7) (8) (9) (11) }\end{array}$ \\
\hline 11. & $\begin{array}{l}\text { Quem acredita na política de retenção do Banco está mais satisfeito } \\
\text { em relação ao trabalho. }\end{array}$ & $\begin{array}{l}\text { (1) (2) (3) (4) (5) } \\
\text { (6) (7) (8) (9) (11) }\end{array}$ \\
\hline 12. & $\begin{array}{l}\text { Me orgulho em trabalhar numa empresa em que a maioria dos } \\
\text { executivos são funcionários de carreira. }\end{array}$ & $\begin{array}{l}\text { (1) (2) (3) (4) (5) } \\
\text { (6) (7) (8) (9) (11) }\end{array}$ \\
\hline 13. & $\begin{array}{l}\text { Acredito que posso ascender na carreira trabalhando no Banco do } \\
\text { Brasil. }\end{array}$ & $\begin{array}{l}\text { (1) (2) (3) (4) (5) } \\
\text { (6) (7) (8) (9) (11) }\end{array}$ \\
\hline 14. & $\begin{array}{l}\text { A oportunidade de trabalhar em outras áreas do Banco, estimula } \\
\text { minha busca por aperfeiçoamento profissional. }\end{array}$ & $\begin{array}{l}\text { (1) (2) (3) (4) (5) } \\
\text { (6) (7) (8) (9) (11) }\end{array}$ \\
\hline 15. & $\begin{array}{l}\text { Me sinto motivado ao ver que o Banco valoriza os talentos de seus } \\
\text { funcionários. }\end{array}$ & $\begin{array}{l}\text { (1) (2) (3) (4) (5) } \\
\text { (6) (7) (8) (9) (11) }\end{array}$ \\
\hline 16. & $\begin{array}{l}\text { As recompensas pelo atingimento de resultados são proporcionais à } \\
\text { minha dedicação ao trabalho. }\end{array}$ & $\begin{array}{l}\text { (1) (2) (3) (4) (5) } \\
\text { (6) (7) (8) (9) (11) }\end{array}$ \\
\hline 17. & $\begin{array}{l}\text { O resultado do meu trabalho é reconhecimento na minha avaliação } \\
\text { de desempenho. }\end{array}$ & $\begin{array}{l}\text { (1) (2) (3) (4) (5) } \\
\text { (6) (7) (8) (9) (11) }\end{array}$ \\
\hline 18. & $\begin{array}{l}\text { As práticas de retenção desenvolvidas pelo Banco impulsionam o } \\
\text { meu desempenho. }\end{array}$ & $\begin{array}{l}\text { (1) (2) (3) (4) (5) } \\
\text { (6) (7) (8) (9) (11) }\end{array}$ \\
\hline 19. & $\begin{array}{l}\text { A liderança exercida pelo meu superior imediato contribuiu } \\
\text { positivamente para o desempenho da equipe. }\end{array}$ & $\begin{array}{l}\text { (1) (2) (3) (4) (5) } \\
\text { (6) (7) (8) (9) (11) }\end{array}$ \\
\hline 20. & $\begin{array}{l}\text { No meu ambiente de trabalho, possuo autonomia para discutir } \\
\text { temas relevantes para o Banco. }\end{array}$ & $\begin{array}{l}\text { (1) (2) (3) (4) (5) } \\
\text { (6) (7) (8) (9) (11) }\end{array}$ \\
\hline 21. & $\begin{array}{l}\text { Os feedbacks recebidos pelas diversas fontes (pares, subordinados, } \\
\text { superiores) impactam no aprimoramento do meu desempenho. }\end{array}$ & $\begin{array}{l}\text { (1) (2) (3) (4) (5) } \\
\text { (6) (7) (8) (9) (11) }\end{array}$ \\
\hline 22. & $\begin{array}{l}\text { Meu superior imediato expõe com clareza o nível de desempenho } \\
\text { esperado pelos integrantes da equipe. }\end{array}$ & $\begin{array}{l}\text { (1) (2) (3) (4) (5) } \\
\text { (6) (7) (8) (9) (11) }\end{array}$ \\
\hline 23. & A política de retenção do Banco funciona. & $\begin{array}{l}\text { (1) (2) (3) (4) (5) } \\
\text { (6) (7) (8) (9) (11) }\end{array}$ \\
\hline 24. & $\begin{array}{l}\text { A política de retenção do Banco faz com que os funcionários } \\
\text { queiram permanecer nesta organização. }\end{array}$ & $\begin{array}{l}\text { (1) (2) (3) (4) (5) } \\
\text { (6) (7) (8) (9) (11) }\end{array}$ \\
\hline 25. & $\begin{array}{l}\text { Quem acredita na política de retenção do Banco é mais } \\
\text { comprometido em relação a quem não acredita. }\end{array}$ & $\begin{array}{l}\text { (1) (2) (3) (4) (5) } \\
\text { (6) (7) (8) (9) (11) }\end{array}$ \\
\hline
\end{tabular}




\subsection{Dados demográficos e funcionais}

26. Qual a sua idade?

27. Qual o seu nível de escolaridade? Indique a opção já concluída.

( ) Ensino Fundamental

( ) Ensino Médio

( ) Ensino Superior

( ) Especialização

( ) Mestrado

( ) Doutorado

28. Há quanto tempo você tomou posse no Banco?

29. Qual o seu cargo?

Muito obrigado pela sua colaboração.

Sua participação foi fundamental para o sucesso deste trabalho. 